A Guide to the use of the LIST OF FLEAT PARTICIPANTS

11 Alpha-numeric listing.

1 Name [ ].

2 Affiliation.

3 FLEAT participation by Event \# or short description.

4 Abstract where applicable. (In the case of multiple presenters, the abstract will appear after the name of the co-presenter whose name appears first in the alpha-numeric listing).

5 Biographical information.

Example \# 1 (Single presenter with abbreviated abstract)

1

1 AlZU, Yo

2 Waseda University, Tokyo, Japan.

334 - presenter

4 Mr. Yo AIZU will present a chronological survey of NHK radio and television programs used to teach foreign languages, with a special emphasis on French language programs.

5 Mr. Yo AIZU, a graduate of the Tokyo Metropolitan University, specializes in the teaching of French at Waseda University.

Note: Mr. AIZU's photograph is to be found in the section PHOTOGRAPHS OF FLEAT PARTICIPANTS. The photograph number will correspond to Mr. AIZU's alpha-numeric entry 1.

Example \# 2 (Multiple presenters with abbreviated abstract. Co-presenters' alpha-numeric entries are given in ()

1. MATSUYA, Hideaki [OGAWA, Tadao 94, OZAWA, Nobuharu 99]

75 2. Tokai University, Kanagawa, Japan.

3. 23.3 - presenter

4. Hideaki MATSUYA, Tadao OGAWA and Nobuharu OZAWA will give a combined presentation on the language laboratory at Tokai University, including its history, current capabilities and future prospects for language laboratories from a technical point of view.

Note: the co-presenters OGAWA and OZAWA are to be found in the list of participants opposite their alpha-numeric entries. Photos are to be found in the section PHOTOGRAUHS of FLEAT PARTICIPANTS. Photograph numbers will correspond to the presenters' alpha-numeric entries in section entitled "LIST OF FLEAT PARTICIPANTS" 


\section{AIZU, Yo}

1 2. Waseda University, Tokyo, Japan.

3. 34 - presenter

4. Mr. AIZU will present a chronological survey of NHK radio and television programs used to teach foreign languages, with a special emphasis on French programs.

5. Mr. Yo AIZU, a gradaute of the Tokyo Metropolitan University, specializes in the teaching of French at Waseda University.

\section{ALATIS, James E.}

2 2. Georgetown University, Washington, D.C., USA

3. 39-panelist; 27-chair; 36-panelist; 1-panelist. "THE FUTURE OF FOREIGN LANGUAGES IN THE UNITED STATES"

4. Over the past few years in the United States, there have been many signs of promise for the future of foreign languages. The aspirations of many foreign language professionals who, since the 1960s, had been waging a losing battle, were focused in the work of the President's Commission on Foreign Language and International Studies, appointed in 1978. The Commission Report, in its turn, provided the impetus for further, stronger measures, among them the formation of a consortium of professional language associations dedicated to furthering the interests of foreign language and international studies and to monitor and influence the government activities which afiect them.

New government legislation has been introduced and a new note of optimism has been heard with the profession itself; however, as the Commission Report noted, the message must go out to the public at large in order to garner the understanding and support of an informed citizenry. In this regard, we must call on the expertise of advanced educational technology not only to improve actual language programs but also to assist in a media campaign of widespread reeducation.

5. James E. ALATIS is the Dean of the School of Languages \& Linguistics and Professor of Linguistics and Modern Greek at Georgetown University. Since 1966 he has served as Executive Secretary/Treasurer of TESOL. He was formerly an English Teaching Specialist with the U.S. Department of State, Chief of the Language Research Section of the U.S. Office of Education, and Fulbright Professor, University of Athens, Greece. Dr. Alatis was a member of the Modern Language Association committee which drafted Foreign Language Programs for the 1970s. $\mathrm{He}$ is joint editor of Language in American Life, the proceedings of a 1977 Georgetown University Modern Language Association conference on the importance of language study in expanding the international dimension of American education. He was recently elected President of the Joint National Committee for Languages (JNCL), a consortium of professional language associations which grew out of the work of the President's Commission on Foreign Language and International Studies, and which has established a lobbying office in Washington, D.C. to work for the benefit of foreign languages. 


\section{ALATIS, Penelope}

3 2. Hammond Junior High School, Alexandria, Virginia, U.S.A.

3. 13 - chair

4. (no Abstract)

5. (no bio info)

1. AMANO, Kazuo

4 2. Otsuma Women's University, Tokyo, Japan

3. 1-panelist, 39 - panelist.

4. (no Abstract)

5. Kazuo AMANO, formerly a Professor of English Language and Literature at the Otsuma Women's College in Tokyo, is FLEAT/LLA Vice President, and serves on the boards of directors of the Japan Association of College English Teachers and the Phonetic Society of Japan.

\section{ANDO, Kenichi}

5 2. Senshu University, Tokyo, Japan

3. FLEAT projects committee; 1 - panelist; 39 - panelist.

4. (no Abstract)

5. Kenichi ANDO, Professor of English at Senshu University and textbook author, is head of the FLEAT Projects Committee.

\section{ANDO, Shoichi}

6 2. Kyoto University, Kyoto, Japan

3. 1 - panelist; 39 - panelist.

4. (no Abstract)

5. Shoichi ANDO, Professor of English at Kyoto University, received graduate degrees from Kyoto University and from the University of Michigan.

\section{ARAl, Toshikuni}

73. FLEAT Facilities Committee

4. (no Abstract)

5. (no bio info)

\section{ARAKAWA, Tsuneo}

82.

3. FLEAT Facilities Committee

4. (no Abstract)

5. Tsuneo ARAKAWA is a Division Manager for the Nippon Grolier Electric Co.

1. AULESTIA, Victor $H$.

9 2. University of Maryland-Baltimore County, Baltimore, Maryland, USA

3. 1-panelist; 10.2 - presenter; 39 - panelist.

VIDEODISC SYSTEMS AND THE LEARNING OF LANGUAGES

AND CULTURES

4. Educators have known for many years that electronic technology could have a significant impact on education. However, the impact 
has Lecn fairly limited and slow in coming. The proposed paper will ailempt to discuss the many reasons why the full potential of tcclinology has not been realized, such as cost, availability of quality courseware, primitiveness of equipment, resistance to change.

This introduction will be as short as possible and will use a number of visuals.

The next part of the presentation will be devoted to an explanation and demonstration of current videodisc technology and general application plus a review of completed instructional pilot discs (gymnastics, psychology, dentistry, emergency medical services, etc.). Once again the lecture will be accompanied by visuals.

The third part of this talk will be devoted to a short lecture on interactive training systems which integrate the optical disc with a microprocessor, keyboard and color television monitor into a single stand-alone, low cost, student oriented leärning terminal.

The last part of this presentation will deal with authoring considerations. It will point out the differences and similarities of authoring for CAI and the videodisc/microcomputer delivery system. If a microcomputer is not available, slides and overhead transparencies will be used.

The observers will have regular opportunities to engage the presenter in discussion, thus enriching the dialogue with comments and questions.

5. Victor H. AULESTIA, NALLD Vice President, is Director, Department of Instructional Media Resources, University of Maryland-Baltimore County, Catonsville, Maryland. Born in Quito, Ecuador, Mr. Aulestia earned the B.S. in Education from California State College and the M.A. from the University of West Virginia. He is a Doctoral Candidate at the University of Maryland.

1. AZUMA, Junichi [NOMURA, Kazuhiro (89) \& YAMANE, Shigeru (145)]

10 2. Amagasaki High School, Japan

3. 22.3 - presenter.

"THE VISUAL EFFECT OF THE SPEAKERS GESTURES ON

AUDITORY COMPREHENSION - FROM THE VIEWPOINT OF MOTOR

THEORY OF SPEECH PRODUCTION AND PERCEPTION"

4. Auditory comprehension is known to be a highly active task in which listeners process the speech sound by reorganizing it into linguistic units through positive rehearsal. It is currently stressed by experimental phoneticians that perceptually isochronous speech rhythm acts as a carrier of linguistic units and facilitates auditory comprehension. Many experimental phoneticians also maintain that such speech rhythm is not determined by linguistic rules, but that there exist some intrinsic neurophysiological principles underlying speech rhythm; though the arguments still remain open.

Considering these current studies in experimental phonetics, it is hypothesized that the rhythm of the speaker's gestures, being rehearsed by the listener in some way, would also facilitate the auditory compre- 
hension if it runs parallel to the speech rhythm. In order to examine the hypothesis, experiments were made in English auditory comprehension under two different conditions. In these experiments, native Japanese subjects, junior college students, were divided into two equal groups and administered the same English auditory comprehension tests; one group was exposed to the Audio portion only-the Video portion of the VTR was switched off-and the other group, in addition to the Audio portion, was exposed to the Video display of the upper half of the speaker's figure. The speaker employed for this study was a 23-year-old Englishwoman.

The results of the experiments show that the Audio-Visual group has achieved better scores than the Audio group and the preliminary hypothesis seems to have been supported. It also became clear that there exists a certain degree of parallelism between the prosodic transcription of the speech and the kinesic transcription of the spearker's gestures.

These results together with current studies in experimental phonetics suggests to students of TELF/TESL that (1) intensive training in English speech rhythm would enhance students' auditory comprehension, (2) VTR material which shows the speaker and his/her gestures would promote the students' intrinsic comprehension ability, and (3) there exist neurophysiological bases in TEFL/TESL approaches stressing students' kinesic activities such as the Total Physical Response Approach.

5. (no bio info)

1. BAILEY, Leslie $\mathbf{F}$.

112. Northwestern University, Evanston, Illinois, USA

3. NALLD Treasurer

4. (no Abstract)

5. Leslie F. BAILEY, Director of the Language Laboratories at Northwestern University in Evanston, Illinois and Treasurer of the National Association of Learning Lab Directors, earned the Doctorate in Slavic Linguistics from the University of Wisconsin.

1. BOCAZ-MORAGA, Sergio

12 2. Eastern Washington University, Cheney, Washington, USA

3. 13.4 - presenter; 29 - chair

IERNALINGUAKINOPOEDIA: PHILOSOPHY AND METHODOLOGY

FOR LANGUAGE INSTRUCTION IN THE 21ST CENTURY

4. VERNALINCUAKINOPODEIA represents a totally new, scientific and philosophical method for teaching a second language. Heavily dependent on a visual mode, this metthodology can be presented on videotape, using the Kodak Ektagraphic Viewer and Super 8 home movies. This method uses elements which are native and well known to the learner. Thus American and local history are favorite themes used to generate rapport and enthusiasm. The role of the teacher 
as a civic leader remains important. VERNALINGUAKINOPOEDIA also demands active student and teacher participation.

5. Professor BOCAZ-MORAGA is an Associate Professor of Spanish at Eastern Washington University in Cheney, Washington.

1. BURGGRAAF, Samuel F.

13 2. Brigham Young University, Provo, Utah, USA.

3. 1 panelist; 31 - chair; 38 - presenter; 39 - panelist.

4. (no Abstract)

5. Samuel F. BURGGRAAF is the Executive Secretary of the National Association of Learning Laboratory Direclors. Mr. Burggraaf was extensively involved in planning the NALLD participation at the FLEAT conference.

\section{CHUJO, Sosuke}

3. FLEAT Vice President

1. DAVIES, Norman F.

152. University of Linkoping, Sweden

3. 27.4 - presenter; 36 - panelist.

TRAINING FLUENCY - AN ESSENTIAL FACTOR IN LANGUAGE ACQUISITION AND USE

4. In language education, three primary aspects of communication should be taken into account: accuracy, appropriateness and fluency. The first, long the traditional goal of teaching, has in recent years been weakened by interlanguage theory and the view that a knowledge of usage alone is insufficient. An overemphasis on Monitor-use (Krashen's terminology) may also adversely affect acquisition, !ead to slow pacing and an impoverishment of language samples preserited in the classroom.

Appropriateness has in recent years been seen as a major factor in achieving communicative competence, now widely accepted (though not always well-defined) as the major goal of language teaching and learning. The rules of use are undoubtedly a suitable field for study, but have perhaps been overemphasized by some proponents; they often differ little between related cultures.

To learn language, however, one must use it, and fluency training is the essential but partly neglected third factor in the learning situation. Fluency is essential in the receptive skills, which should be given early priority and trained by constant exposure to and processing of a wide variety of preferably authentic materials. It is highly desirable in the productive skills, and requires the frequent use of genuine and stimulating communicative exercises in the classroom, which not only increase fluency but are a major vehicle of language 
acquisition. Examples will be given of methods of training fluency, in the classroom and in the learning laboratory.

5. Professor Norman F. DAVIES is Chair of the Department of Language \& Literature at the University of Linkoping, Sweden. In addition to founding and editing System, an international journal for educational technology and language learning, Dr. Davies has published extensively in the fields of language teaching methodology and modern English poetry.

1. DOBLE, Gordon

16 2. University of Bradford, England

3. 10.1 - presenter.

THE LANGUACE LABORATORY AND AUDIO WORKROOM IN THE ADVANCED TEACHING OF FOREIGN LANGUAGES

4. The use of technological aids in Modern Languages Degree courses in Universities poses a number of theoretical and practical problems. Experimentation has tended to concentrate on exercise types and skill training. Experience at the University of Bradford suggests that more emphasis should be placed on investigating the nature and role of monitoring, and on the place of the Audio Workroom in the learning process. The separation of teaching and learning processes helps to define more explicitly the contributions the different kinds of installation can make.

5. (no bio info)

1. FUJISAKI, Masayuki [GOTO, Shuji (18); KIMURA, Yoichi (51); MATSUMOTO, Takashi (74), YAMADA, Akitoshi (142]

17 2. Matsushita Communications, Audio Video Division, Japan

3. 30.1 - presenter.

LL HEADPHONE SYSTEM SIMULATING NATURAL SOUND HEARING

4. Headphone listening, which is widely used for language laboratory systems, has two major advantages. First, the sound energy from headphones is localized to the listener and does not bother others. Secondly, the headphone listener is not bothered by outside noise which would otherwise intrude into the reproduced sound field. However, in comparison with loudspeaker listening (or natural hearing), headphone listening to conventional $\mathrm{LL}$ program sources has been revealed to have the following two problems:

(a) The reproduced sound remains "within" the area of the head (which we call in-head localization), and makes the listener feel like being stimulated at the center of the brain.

(b) There exists a considerable difference in reproduced sound quality.

The problems mentioned above seem to cause LL students to have impressions of unnaturality and uncomfort during language study, especially when lessons last for many hours, and furthermore, it is feared that these factors might even suppress learning progress. 
Our research is based on the natural hearing mechanism, where listeners can determine sound image localization outside the head. In natural hearing inside an ordinary room with proper reverberation, listeners perceive not only direct sound from a sound source, but also indirect sound which is reflected from the walls, ceiling, and floor of the room, and which may reach each ear from many different directions.

On the other hand, in headphone listening to conventional sound sources, especially in case of monaural sources, when two completely equivalent signals are transmitted to the listener's each ears without any room reflections, there seem to be no cues for listeners to judge the sound coming from outside. In this manner in-head localization occurs.

We applied the hearing mechanism explained above to our new LL headphone systems, which carry two independent (stereo) channels, (even though the tape sources are conventional monaural) and incorporate electronic delay circuits which produce sound reflections in such a way that listeners can perceive correct sound quality as well as sound distance (out-of-head localization) just like in natural sound hearing. Such systems simulate the actual sound field of daily conversation, and are expected to remove the fatique associated with conventional LL headphone listening and to greatly improve educational efficiency.

5. (no bio info)

1. GOTO, Shuji [FUJISAKI, Masayuki (17); KIMURA, Yoichi (51); MATSUMOTO, Takashi (74); YAMADA, Akitoshi (142)]

18 2. Matsushita Communications, Audio Video Division, Japan

3. 30.1 - presenter

4. For abstract see FUJISAKI, Masayuki.

5. No bio info

1. HAGIWARA, Nathaniel Tsutomu

192 . Senshu University, Japan

3. FLEAT Committee-Publications

4. (no Abstract)

5. Nathaniel Tsutomu HAGIWARA, Professor of English at Senshu University, is the co-editor of Studies on the Language Laboratory, which is being published exclusively for the FLEAT convention. A graduate of Aoyama Gakuin and Rikkyo universities, Professor Hagiwara's writings have appeared in Studies in English Literature (the English Literary Society of Japan), The Annual Bulletin of the Humanities (Senshu University), The Rikkyo Review, and others. In late 1980, he received the Senshu Foundation fellowship. He is also active in the fields of Instructional Technology and American Studies. 


\section{HAMBROOK, Joe}

20 2. British Broadcasting Corporation, London, England

3. 1 - panelist; 34 - presenter; 39 - panelist.

\section{WHO CONTROLS WHAT?}

4. Who are the people and what are the factors that control the design, production and use of Multi-Media course materials for Foreign Language Learners? What effect do they have on content, methodology and (most important of all) the needs and interests of learners themselves? Who is getting the best deal out of the technologies, resources and opportunities available? Indeed, is there any evidence of a systematic or logical approach to this problem? Developments in language teaching and advances in audio-visual technology have prompted a closer look at these questions. This presentation will consider them from the perspective of all concerned in making and using course materials, but the main response to these questions will be that of a producer of multi-media materials for international use. There will be illustrations and case studies from a wide range of course materials which have been used in many different countries and contexts. Finally, there will be a brief consideration of the future prospects for multi-media course materials in the light of the lively constraints and opportunities arising from the introduction of new forms of video hardware.

5. Joe HAMBROOK is the Executive Director of English by Television at the British Broadcasting Corporation. Mr. Hambrook is in charge of the production of film, television and video materials for the teaching of English as a second language.

\section{HARVEY, T. Edward}

21 2. Brigham Young University-Hawaii Campus, USA

3. 1 - panelist; 11.1 - presenter; 39 - panelist.

\section{RATE-ALTERATION TECHNOLOGY AND ITS \\ PLACE IN THE LANGUAGE LAB}

4. Second language learners come to the language lab with differing abilities, differing backgrounds, and differing psychological makeups. Some are good listeners, some are poor listeners--even in their native languages-but the majority suffer from anxiety brought on by the psychological factor operating within them as they respond to standard recorded listening programs. Field dependent (Witkin, 1962) listeners show high anxiety when confronted with a rapid string of speech sounds (Steer, 1945) because they are in a task overload condition. Errors increase and there is a tendency to revert to previously learned generalizations-in this case the learner's native language. The resulting situation is mis-comprehension and de-motivation.

The present paper describes rate-alteration technology. It suggests expanded speech as a means of varying the language velocity so that the language lab can be used in part to eliminate the negative psychological effects of too much speed. Beginning students expecially 
benefit from the application of rate-alteration to standard lab programs. Native speed can be made comprehensible without sacrificing fidelity thus increasing student motivation. Applications are suggested and the speech compressor-expander is offered as a tool to eliminate stress in the language lab.

5. T. Edward HARVEY, Ph.D. in Foreign Language Education, The Ohio State University, is Assistant Professor at the Brigham Young University-Hawaii Campus where he teaches Spanish, French, and coordinates the Foreign Language Program. He has published articles in the NALLD Journal and the TESL Reporter. His professional affiliations include membership in ACTFL, PNCFL, NALLD, TESOL, AATSP, and HALT.

\section{HATANAKA, Takami}

22 2. Tohoku Gakuin University, Sendai, Japan

3. 18 - presenter

THE USE OF BROADCASTING: PAST, PRESENT AND FUTURE

4. Takami HATAKANAKA will discuss the history, current state and future developments in the use of radio and television at the senior high school level in Japan.

5. Takami HATANAKA, Professor of English at the Tohoku Gakuin University, has published extensively in the fields of English Language \& Literature.

\section{HATORI, Hiroyoshi}

23 2. Tokyo Gakugei University, Japan

3. FLEAT Advertising Committee; 18 - chair; 34 - chair.

4. (no Abstract)

5. Hiroyoshi HATORI, Professor of English at the Tokyo Gakugei University, received the M.A. in Education from Tokyo University.

\section{HATTORI, Tatsuo}

25 2. Fukuoka City Hama Junior College, Japan.

3. 1 - panelist.

4. (no Abstract)

5. (no bio info)

\section{HAYASE, Mitsuaki}

24 2. Kansai Junior College of Foreign Languages, Katano, Japan.

3. 27.1 - presenter.

\section{STUDY AND PRACTICE OF PUBLIC SPEAKING}

\section{AND STORYTELLING IN THE LANGUAGE LABORATORY}

4. The author has been teaching public speaking and storytelling using the facilities equipped in the language laboratory for more than two years. He has also been videotaping some of the teaching materials in cooperation with American speech specialists.

In this paper through the close observation of the videotapes of the 
teaching materials and students' presentations, he will discuss (1) the technical problems in videotaping and (2) the problems and difficulties in teaching public speaking and storytelling in the language laboratory.

5. Mitsuaki HAYASE, a Lecturer at the Kansas Junior College of Foreign Languages, earned the M.A. from Kansai University. He has published several books and articles on the topics of Speech Communication and Public Speaking.

1. hiRASAKA, Fumio [KAMATA, Seizaburo (45)]

26 2. Sophia University, Tokyo, Japan

3. 19.3 - presenter.

AN ACOUSTIC STUDY OF THE DIFFERENCES

BETWEEN AMERICAN ENGLISH AND IAPANESF. DIPHTHONGS

4. It has been insisted in the field of articulatory or traditional phonetics that English diphthongs /al/ and /OI/ (hereafter/al/e and /OI/e) are strikingly different from what is called Japanese diphthongs /ai/ and /oi/ (hereafter /ai/j and /oi/j). Up to now, however, few studies have been made which compare English and Japanese diphthongs acoustically and investigate the difference between them. We consider that to comparison and examination of the acoustic difference is not only interesting from the view point of phonetics but significant for the training of English pronunciation.

In our previous study (Sophia Linguistics 1981, forthcoming), we analyzed quantitatively the area occupied by the first and the second elements of $/ \mathrm{al} / \mathrm{e}, / \mathrm{Ol} / \mathrm{e}, / \mathrm{ai} / \mathrm{j}$ and $/ \mathrm{oi} / \mathrm{j}$ respectively in the physical space of American English and Japanese monophthongs and the differences of duration in the first and second elements.

In the present study, we reconsider the results obtained in the previous study more quantitatively and measure formant transition from the first to the second element in terms of the step-wise response model of the critically dumped second order linear system, and inquire into the difference in transition between American English /al/ and /OI/ and Japanese /ai/ and /oi/. We assume that one factor which yields the difference in formant transition is how the first and second elements are stressed, so we also measure acoustically how each element in $/ \mathrm{al} / \mathrm{e}, / \mathrm{Ol} / \mathrm{e}, / \mathrm{ai} / \mathrm{j}$ and $/ \mathrm{oj} / \mathrm{j}$ is stressed and investigate the difference between English and Japanese diphthongs.

5. (no bio info)

\section{HOFF, Roma}

27 2. University of Wisconsin-Eau Claire, USA.

3. $\mathbf{1 2 . 3}$ - presenter.

FROM CONTROLLED COMPOSITION TO CREATIVE COMMUNICATION IN BEGINNING SPANISH

4. Chastain states that in the case of oral skills, less importance is attached to the receptive skill, listening, while in the written skills, less importance is attached to the productive skill. (Developing 
Second-Language Skills: Theory to Practice, second edition, Rand McNally, Chicago, 1976). Indeed, writing is often the forgotten skill in first year foreign language classes. Sometimes the teacher believes that the student should be limited to the listening and speaking skills, sometimes he/she doesn't know how to integrate composition into first and second semester instruction.

This presentation proposes to show that beginning students can write very well in "controlled composition" situations. It further proposes to show how this can be accomplished. Five specific techniques will be described and examples will be given from classroom compositions in Spanish.

Finally, application of the written descriptions, verb game stories, dialogues and playlets, interview questions and personal letters to language laboratory work and testing/evaluation will be discussed.

5. Roma HOFF is a professor of Spanish at the University of WisconsinEau Claire

1. HONDA, Yoshinori

28 2. Tokyo Keizai University, Japan

3. 26.2 - presenter.

SOME THOUGHTS REGARDING THE TEACHING OF SPOKEN ENGLISH THROUGH THE LANGUAGE LAB

4. In the 60s and 70s, the teaching of English in Japan stressed reading skills rather than verbal fluency. Now, however, new requirements for verbal skills in English are being made upon the system. Professor HONDA will discuss the relative merits, motivation and methodology for teaching spoken English in the language laboratory.

5. Yoshinori HONDA, a Professor of English at the Tokyo Keizai University, earned the M.A. from Columbia University.

1. HUTCHINSON, Joseph C.

29 2. Defense Language Institute, Monterey, California USA

3. Event $7.2 ; 1$ - panelist; 11 - chair; 7.2 - presenter; 19 - chair; 39 - panelist.

\section{THE HISTORY OF FOREIGN LANGUAGE EDUCATION AND}

THE USE OF TECHNOLOGY IN THE U.S.A.

4. This will be a summary of the history of technology as applied in foreign language education and training in the U.S.A. Attention will be given to trends over the years including some fads, as well as those enduring long-term combinations of hardware and software. Difficulties encountered in matching methods and materials with media will be explained. The presentation will deal with relationships between principles of instructional systems development with its five phases of analyze, design, develop, implement and control (quality) and the role of technological innovations. The myth of machines replacing people will be mentioned in the context of the role of the instructor as manager of learning. 
5. Joseph C. HUTC.HINSON, Director of Training Development at the Defense Language Institute, Monterey, California, received the Doctorate from the University of North Carolina. Dr. Hutchinson was the Language Laboratory Director at the University of North Carolina and at Tulane University in New Orleans.

\section{IBAYAMA, Michiko}

30 2. Fukui University, Japan.

3. 25 - recorder.

4. (no Abstract)

5. (no bio info)

1. IKARI, Yukio

312. Kobe City University of Foreign Studies, Japan.

3. 36 - recorder.

4 (no Abstract)

5. Yukio IKARI is a graduate student at the Kobe City University of Foreign Studies. He has published extensively in the field of teaching English to children.

1. IKEURA, Sadahiko

322.

3. LLA of Japan - Chapter Representive

4. (no Abstract)

5. Sadahiko IKEURA, LLA Kyushu Chapter representative, earned a Diploma in Applied Linguistics at the University of Edinburgh, Scotland.

1. INAGAKI, Shigeko [ISHIDA, Toshiko (36) \& NAKAMURA, Taeko (84)]

33 2. International Christian University, Tokyo, Japan

3. 28.1 - presenter.

AN EXPERIMENT ON STANDARDIZATION OF JAPANESE PROFICIENCY TESTS -AURAL COMPREHENSION TEST VS. READING COMPREHENSION TEST-

4. This is an interim report of research on standardizing Japanese proficiency tests started in 1977.

Four types of objective Japanese tests-aural comprehension (A), reading $K A N J(R)$, writing $K A N J I(W)$ and grammar \& reading comprehension $(C)$-for non-Japanese students at elementary and intermediate levels were made and administered several times as a pilot study at International Christian University in 1977 and 78 . They were revised, based on the results of the pilot study, and administered again for norming purposes at institutions in Japan and abroad which offered Japanese language courses.

In this paper the results of the tests-means, S.D., frequencies, correlations between the tests, the items and the sub-groups of the items, reliability coefficients, item analyses, factor analyses, cluster analyses etc.-especially of $A$ and $C$ tests-are discussed. 
The $A$ test showed rather peculiar behavior. The items using minimal pairs to discriminate sounds and accent were proved to be too easy and have very low discrimination power. According to the results of factor analyses, they were quite independent-they measured something quite different from what other groups of items measured.

It has been reported, that according to the results of a French test for American students and an English test for Japanese students, the correlations between hearing skill and other skills were rather high. In our experiment, on the contrary to the above report, every revised A test showed rather low correlations with other tests. On the other hand, the $R$ and the $C$ tests had always high correlations with other tests and also with the total of the four tests.

Other results obtained so far in this experiment seem to indicate fundamental differences between English (or other western) language learning and Japanese language learning.

5. (no bio info)

\section{INOKUCHI, Muneo}

34 2. Tobata Senior High School, Shimonoseki, Japan

3. 26.3 - presenter.

\section{ELECTRONIC EQUIPMENT AS A USEFUL EDUCATIONAL TOOL}

4. Individualizing instruction is well on the way to becoming an accepted procedure in many schools across the nation.

Accordingly, for the practicing teacher this implies a need to provide students with a wide variety of learning experiences.

Because of differences in background and ability, students learn something best by directly participating in the new experience or activity. In today's school the teacher cannot rely on talk and chalk alcne. For tht complex task of teaching, an extensive range of materials and methods is available.

An instructional aid is any device that assists an instructor in transmitting to a learner facts, skills, attitudes, knowledge, understanding, and appreciation. An outstanding development in modern education is the growth in the use of audio-visual aids for instruction. It is natural that in education we should appeal to the mind chiefly through the visual and auditory sense organs.

According to a study made up by the Japanese Language Research Institute, today's four-year-olds can read and write as well as sixyear-olds could in the era before television. Obviously the electronic tube is a powerful educational instrument, aside from whatever deleterious effects it might have.

The use of audio-visual aids such as tape recorders and language laboratories will provide practice in learning, speaking and listening situations.

It is useful in language learning for all to take part in discussion, debate, play and other interesting activities in order to avoid tiresome routine on the path of learning. 
This presentation will focus on the problem of fostering communicative competence among the vast majority of secondary school students who suffer from a lack of motivation, and/or talent.

5. Muneo INOKUCHI, a teacher at Tobata Senior High School, has also served as a Seminar Director at the Fukuoka Prefectural Education Center and as an Instructor at Kyushu Joshi University.

\section{INOUE, Fumio}

35 2. Fukuoka Seiryo Senior High School, Japan.

3. 21 - chair.

4. (no Abstract)

5. (no bio info)

1. ISHIDA, Toshiko [INAGAKI, Shigeko (33) \& NAKAMURA, Taeko (84)]

36 2. International Christian University, Tokyo, Japan.

3. 28.1 - presenter.

4. For abstract see INACAKI, Shigeko.

5. Toshiki ISHIDA, on the faculty of the Division of Languages at the International Christian University, has taught Japanese at the universities of Stanford, Harvard and Paris. She is also the producer of several computer and media programs for teaching Japanese.

1. ISHII, Satoshi [KLOPF, Donald (57)]

37 2. Otsuma Women's College, Tokyo, Japan

3. 27.3 - presenter.

EDUCATING STUDENTS FOR COMMUNICATION WITH PEOPLE FROM OTHER CULTURES

4. In the contemporary world it seems clear that even in the remote corners of the world, intercultural contact is a reality. The consequences can be enjoyable if new friendships are formed and horizons broadened. Or, they can be unpleasant if disunderstandings occur and violence erupts. Unintentional conflict can be avoided when persons of different cultures communicate. Being aware that differences might exist helps prepare one for intercultural encounters. The key, perhaps, to educating students for communication in a multicultural society is exactly that: teaching them about the components of intercultural communication and making them aware of the characteristics that distinguish one culture from another.

The purpose here is to review the major components of intercultural communication and to describe a program of multicultural awareness for students which incorporate the components. For presentation purposes, the components are organized into three divisions: (1) the determiners of behavior, (2) the causes of behavior differences among people, and (3) the ways people confront the unknown. Each needs to be considered in educating students for communication in a multicultural society. In the program described here, these components form the foundation for its development.

The program is the Hawaii Multicultural Awareness Project developed 
by the Curriculum Research and Development Group (CRDG) of the University of Hawaii's College of Education, aimed at students of all ages and in most grades.

The program incorporates the following goals and objectives: (1) to provide the student with information on other cultures: (2) to prepare the student to accept and be tolerant of needs, values and beliefs that are different from his or her own; (3) to provide the student with appropriate behavorial responses in situations where the characteristics of another culture prevail; (4) to prepare the student to anticipate, understand, and cope with the frustrations of cultural shock; (5) to provide the student with an understanding of his or her own culture and the problems caused by cultural bias; and (6) to help the student develop a positive feeling toward multiculturai experiences which will make them enjoyable, interesting and broadening.

5. Satoshi ISHIII is an Assistant Professor at the Otsuma Women's College in Tokyo.

\section{ISHIKAWA, Tatsuro}

38 2. Tokyo Metropolitan Toyama Upper Secondary School, Tokyo, Japan

3. FLEAT Hotels and Tours

4. (no Abstract)

5. Tatsuro Ishikawa, a high school teacher at Tokyo Metropolitan Toyama Upper Secondary School, has a BA from Saitama University.

\section{ITAKURA, Takeko}

392. Fukuoka Jo Gakuin Junior College, Japan

3. 1-panelist; 39 - panelist.

4. (no Abstract)

5. Takeko ITAKURA, Professor of English at the Fukuoka Jo Gakuin Junior College, earned the M.A. from the University of Texas. Professor ITAKURA is also a member of the FLEAT Auditing Committee.

1. IZUMI, Masuko

40 2. Seinan Gakuin University, Fukuoka, Japan

3. 7.1/2/3 - recorder; 3 - host.

4. (no Abstract)

5. Masuko Izumi, is a professor of English with an MA from Baylor University in Texas.

1. JAMES, Eric $F$.

412. University of Toronto, Canada

3. 19.1 - presenter.

PITCH VISUALIZATION AND THE TEACHING OF INTONATION

4. In the area of second language learning, prosodic features (intonation, rhythm, stress) have, for a long time, been neglected in favour of problems of articulation only. Thanks to relatively recent research, we know that speech prosody is a very important aspect of inguistics which, if not acquired, can seriously hamper communicative competence. For this reason it is held by many experts in the field that it should be mastered even before articulatory niceties. In 1963, Harlan 
LANE (Ann Arbor, Michigan) conducled an in-depth study of the acquisition of prosodic features, a study which was continued and modified at the University of Toronto thanks to the invention of the MARTIN pitch analyzer/visualizer.

Whereas the Lane experiments gave the student his personal feedback on a meter (the more the needle departed from zero the greater the difference from the model), the Toronto experiments visualized in real time the actual model intonation curve on an oscilloscope. Furthermore, the student's imitation was visualized instantaneously, and in a similar fashion below the model curve - thus permitting an instant visual comparison of model and imitation. When the student repeated his imitation his previous attempt was erased and his new imitation was visualized as before. This process continued until mastery was achieved.

The learning experiments undertaken with the visualizer and the results which spring therefrom are described in detail, as well as the integration of the visualizer in the normal learning sessions of the language laboratories at the University of Toronto.

A videotape showing pre-conditioning session material will be presented, as well as a demonstration of the visualizer itself.

5. Eric F. JAMES received the M.A. from the University of Toronto and a degree in Applied Phonetics from the University of Aix en Provence, France. He has taught elementary school as a general teacher and as a specialist in French, using the audio lingual method. He has been at the University of Toronto since 1967. He is presently an Associate Professor of French Linguistics and Director of the Language Laboratory at University College of the University of Toronto. His special interest are corrective phonetics and applied linguistics. He has published numerous articles on phonology, corrective phonetics and second language learning.

\section{JOHNSON, Teresa}

42 2. Saint Louis University, St. Louis, Missouri, USA

3. 21.3 - presenter.

MEDIA AND THE DEVELOPMENT OF ADVANCED LANGUAGE SKILLS

4. Advanced students are generally able to communicate, at some basic level, most ideas and feelings. Accuracy is often lacking, with speed being affected often by search of words or structures. Still, there is a feeling of general adequacy which prevents the student from developing as fast as the beginning student. Accomplishment is more difficult to detect at the advanced level, since greater fluency and accuracy in communication are more difficult to develop than a simple accumulation of short sentences and vocabulary.

In order to provide the advanced student with models and with a reliable measure of his/her communicative skills, video tapes, tape recordings and overhead projector have been used. Commercial video tapes provide opportunities for students to develop knowledge about social rules and conventions of conversational interplay necessary for 
appropriate interaction in the foreign language. Student-produced video tapes, on the other hand, allow for immediate feedback and, given proper analysis of performance, achieve greater balance between his/her knowledge of linguistic rules and structures, and performance, use, of same. Most advanced students recognize pronunciation and syntactic errors readily enough when correcting compositions or critiquing video-taped performance. Awareness of areas of difficulty provides needed self-monitoring which results in the development of oral and written skills at the advanced level.

This presentation will discuss the systematic use of videotapes (commercial and student-produced), recordings and other language learning center equipment to develop accuracy and fluency in oral and written foreign language skills and enhance auditory comprehension.

5. Professor Teresa Herrerade JOHNSON was born in San Luis Potosi, Mexico. She is currently an Associate Prolessor of Spanish at Saint Louis University in St. Louis, Missouri. Dr. Herrera-Johnson earned the Doctorate in Applied Psycholinguistics at Saint Louis University.

1. JUNG, Udo O. $\mathrm{H}$.

43 2. University of Marburg, Germany

3. 20.3 - presenter; 1 - panelist; 39 - panelist.

THE ROLE OF EDUCATIONAL TECHNOLOGY IN

FOREIGN LANGUAGE DYSLEXIA

4. In the Federal Republic of Germany, dyslexic students cannot and should not be prevented from learning foreign languages. At least one foreign language, English in most cases, is an obligatory subject in the German school system.

According to some sources, dyslexia in German schools amounts to between 20 and 30 per cent of the total school population. It is a serious problem, even if the above-quoted figures should turn out to be overestimations.

In my paper I will give an overview of the German research into dyslexia-situation, and 1 will present data from a research project involving $\mathbf{1 1 3}$ dyslexic and $\mathbf{2 7 5}$ normal students from all over Germany, who wrote a dicto-comp at the end of their second year in English as a foreign language.

The notion of "reversals" as indicative of dyslexia in the mother tongue as well as in a foreign language will be seriously questioned. The problems confronting dyslexic students of a foreign language are of a different nature.

Finally an attempt will be made to indicate which role technical media (language labs, micro- and pocket computers) can play in the remedial training of dyslexic students.

5. Educated at the universities of Freiburg and Edinburgh, Professor JUNG was Language Laboratory Director at the University of Kiel, Germany from 1970 to 1977 . He is presently deputy director of the Foreign Language Research Information Center at the University of Marburg (Germany). 
1. KADOTA, Shuhei

442. Assumption High School, Osaka, Japan.

3. 20.2 - presenter.

\section{SOME PSYCHOLINGUISTIC EXPERIMENTS ON THE PROCESS OF READING COMPREHENSION}

4. Some attempts were made to explore the process of reading comprehension of Japanese students learning English as a foreign language. A brief survey of psycholinguistic studies on reading comprehension reveals that a reader divides and organizes the written material into larger syntactic units such as phrases, clauses, etc. through active use of linguistic information in his long-term memory. More recently, however, the semantic information of a sentence has been proven to play a more decisive role than the syntactic information in the processing of the written material.

Experiment $I$ of the present study concerns itself with the units of reading comprehension. The subjects (10th and 11 th grade students), divided into three experimental groups, were presented with the written material in three different modes: (1) regular sentences, (2) sentences with slashes at the boundaries of low level semantic units, and (3) sentences with slashes between words. The main result is that the group presented with the second type of material comprehended the text significantly better than the other groups, which shows that the unit of comprehension in reading is not a single word, but some semantic units such as a phrase. However, when the junior college students were tested with the same material, this difference of comprehension rate disappeared. This can be taken as the evidence that the unit of reading is flexible, and not fixed on a low level semantic chunk.

In experiment 11,12 th grade students were required to memorize the forms and the meanings of the 15 sentences, one at a time, which were gradually increased in length. The main results are that the subjects remembered the meaning of a sentence better than the actual form of it, and that function words were more likely to be forgotten than content words. The results from the two experiments support the semantic view of reading comprehension, which suggests that comprehension consists of synthesizing atomistic propositions into large conceptual or semantic units.

5. Shuhei KADOTA, a teacher at Assumption High School in Osaka, received the M.A. degree in English Linguistics from Kobe City University of Foreign Studies and has conducted research in the areas of Psycholinguistics and Foreign Language teaching.

1. KAMATA, Seizaburo [HIRASAKA, Fumio (26)]

45 2. Sophia University, Tokyo, Japan

3. 19.3 - presenter.

4. For abstract see HIRASAKA, Fumio.

5. (no bio info) 
1. KANEDA, Masaya.

46 2. Nagoya Gakuin University, Japan.

3. 36 - panelist.

4. (no Abstract)

5. Masaya KANEDA, from the Nagoya Gakuin University, is a LLA Chapter representative.

1. KAPLAN, Robert

472. University of Southern California, Los Angeles, California, USA

3. 1 - chair; 31 - presenter; 39 - chair.

ELECTRONIC MEDIA, INSTRUCTIONAL TECHNOLOGY AND LANGUAGE INSTRUCTION IN PLANNING THE USE OF ENGLISH

AS A LANGUAGE OF WIDER COMMUNICATION IN NON-ENGLISH SPEAKING COUNTRIES

4. For a variety of complex reasons, English has become the international language of wider communication in the sciences and in a number of other fields. The reasons underlying this phenomenon are briefly discussed. Then the implications of this phenomenon are discussed in detail. Non-English speaking countries have limited numbers of alternatives available to them for coping with this phenomenon; the alternatives are listed and discussed in some detail. The general area of "Information Science" and the sub-field of "Information Management" are defined, and the implications of the brcad-range use of English with respect to Information Science and Information Management are explored. The uses of electronic teaching media are looked at in terms of the whole broad field of Information Science and Information Management. Since little is presently known about the language needs of Information Scientists and Information Managers, a number of recommendations are presented for the consideration of specialists in mediated instruction and the technology of language teaching. International cooperation is absolutely necessary if this little-understood area is to be intelligently attacked and if solutions based in appropriate technology are to become available. The broad outlines for areas of international cooperation, with particular attention to Japan and Asia, are laid out.

5. Dr. Robert KAPLAN is Professor of Applied Linguistics at the University of Southern California.

1. KATO, Tadahiko

48 2. Okazaki-Mikawa Junior High School, Japan.

3. 18 - presenter; 34 - presenter.

4. (no Abstract)

5. Tadahiko KATO, graduated from Nanzan University and is an instructor at Mikawa Junior High School.

1. KAY, Michael

49 2. University of York, Ontario, Canada.

3. 23-chair; 28 - chair; 1 - panelist.

4. (no Abstract)

5. (no bio info) 
1. KESSLER, Michael

50 2. San Francisco State University, San Francisco, California, USA

3. 11.2 - presenter.

\section{THE ORGANIZATION O: $\triangle$ TAPE TAKE-HOME SERVICE}

4. This paper will discuss the rationale and organization of a university audiotape, take-home service. Professor KESSLER will also discuss the cost-effectiveness of such a service when measurered against the expense of a large, in-house language laboratory.

5. Dr. Michae! KESSLER earned the Dociorate from the University of Chicago. He has taught languages at the University of Chicago, Northwestern University and the University of Michigan-Flint. He is currently the Director of the Language Laboratory at San Francisco State University.

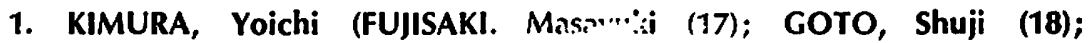
MATSUMOTO, Takashi (74); YAM!ADA. Ak:toshi (142)

51 2. Matsushita Communications, Acoustic Research Laboratory, Japan

3. 30.1 - presenter.

4. For Abstract see FUJISAKI, Masayuki.

5. (no bio info)

1. KIRK, Tim

52 2. Asian Institute of Technology, Bangkok, Thailand

3. 12.2 - presenter.

UP THE CREEK WITH A PADDLE - ESSENTIAL PREREQUISITES TO EXTENDED LISTENING

4. Listening comprehension involves dividing up the stream of sound correctly into segments of morphemes, words and sense groups. Foreign language learners often perform poorly in this respect when faced with the need for extended listening and information extraction in an extended audio context, in spite of many years of previous instruction. While still maintaining the ultimate aim of listening for information extraction, such learners should be given practice in the recognition of features of the rapid spoken language, including rhythm, word and sentence stress, and accompanying phonetic variation, elision and liaison at word or morpheme boundaries. Sample exercises based on English are given for language laboratory or classroom use. In order to properly illustrate his presentation, Professor KIRK will use an overhead projector and an audio lape recorder.

5. Tim KIRK, an Assistant Professor and Associate Director of the Language \& Media Center at thie Asian Institute of Technology in Bangkok, received an M.A. in Applied Linguistics from the University of Reading, England.

\section{KITA, Hiroshi}

53 2. Ishikkawa Technical College, Kanazawa City, Japan.

3. 28 - presider.

4. (no Abstract) 
5. Mr. Hiroshi KITA, Associate Professor of English and Chairman of the Department of English at Ishikawa Technical College, earned the M.A. in Education at Temple University, Philadelphia, Pennsylvania.

\section{KITAO, Kenji}

54 2. Doshisha University, Kyoto, Japan

3. 22.4 - presenter.

\section{TEACHINC AMERICAN CULTURE IN ENGLISH CLASSES}

4. The purpose of language is communication. However, full communication cannot be accomplished by language alone. Without a shared understanding of a cultural background, no one can communicate well with anyone else, even if he/she is adroit at manipulating language.

The cultural aspects of the English language are becoming more and more important to Japan because of the increasing diplomatic, economic, academic, and cultural relations with the United States. More Japanese people now encounter more American people, products, information, and culture on a daily basis than ever before. As such encounters increase, more misunderstandings and miscommunications occur. These arise not only because of language barriers but also because of cultural barriers.

In the English-teaching profession in Japan, American culture has been emphasized recently because of the stress on communication. However, it is taught neither extensively nor well. There are not many studies to show how culture is important and how well it is taught in English classes.

I conducted four studies which were intended to indicate the aspects of culture which most impede communication between Japanese and Americans. These studies were (1) the administration of questionnaires to fifty-two Japanese students in the Unied States, (2) an examination of Japanese junior and senior high school English textbooks, (3) the administration of the Test of American Culture to twenty American college students, forty Japanese students at the University of Kansas, and a hundred and sixty students in Japan, and (4) interviews with twenty newly-arrived Japanese students at the University of Kansas.

The results of four studies show that there is an inadequate foundation for good understanding and communication between the Americans and Japanese. The Japanese students had been taught very little about American culture in English courses of any level and they did not understand American culture well. As a result, they had problems understanding Americans and communicating with them.

In this presentation, I will explain what areas of American culture should be taught, and how they should and can be taught in English classes, using the above studies and An American Sampler, a new textbook for college students.

5. Dr. Kenji KITAO, presently on the faculty at Doshisha University, earned his M.A. and Ph.D. at the University of Kansas. He has edited 
and published many arlicles both in Japan and abroed. Professor KITAO is presently Vice President of the Japan Association of Language Teachers (JALT).

1. KITIZAWA, Kaori

55 2. St. Paul, St. Paul's School, Concord, New Hampshire, LISA

3. 28.2 - presenter.

NEUROLINGUISTIC FOUNDATIONS IN THE EVOLUTION OF LEARNING METHODS AND NECESSARY TECHNOLOGY IN THE

TEACHING OF JAPANESE AS A SECOND LANGUAGE

4. In our present program we unify a growing body of neuroscientific knowledge in regard to the structure and function of the cerebral cortex to issues in the selection of methods and the use of audio and visual technology in a design for teaching a full year course in beginning Japanese in a classroom setting.

The course is a thirty week program, with seven students, five of whom are secondary school students with better than average ability, and two faculty, one, a head of the modern language depar'ment. Course materials center on a modification of the Winitz and Reeds (1973) method: "Rapid acquisition of a foreign language by the avoidance of speaking", an approach used in some centers in lapan for teaching English (Pendergast, 1979). Forly programs of sets of short story line pictures are related to corresponding audio cassette tapes. The emphasis is on verbal and semantic comprehension. The learner must choose pictures which correspond to the meaning of words or sentences. After basic grammer and vocabulary are well learned, talking may start. By postponing pronunciation the asthors claim that the result is more like the acquisition of native speech. We have modified some of the technical dimensions and timing in the presentation of these materials.

The structure of the course is an interrelated program of: 1) self paced study with audio and video arrangemen's of verbal comprehension materials. 2.) complete ad lib use of tutor. 3.) community excersizes stressing comprehension and generative competence. 4.) later self paced addition of language modes. The aim of the course is to emphasize all language modes - listening, speaking, reading and writing, through an extended examination of auditory verbal comprehension. Throughout the program students have demons.' rated their record in progress though a careful testing of: Japanese comprehension; oral production; conscious understanding of grammatical structure and meaningful practice within a context where the ivordmeaning relationship is of primary importance; reading and writing (Kana).

5. Kaori KITIZAWA attended Seikei School in Tokyo and is a graduate of St. Paul's School, Concord, New Hampshire. She is currently engaged in study and research on the acquisition of lapanese as a first and second language. 


\section{KIYOKAWA, Hideo}

56 2. Wayo Women's University, Tokyo, Japan.

3. 20.1 - presenter.

WORD DIFFICULTY AS A READABILITY VARIABLE

4. Individualized foreign language programs require many elements: instructional objectives, teaching strategies, the selection of instructional resources, the organization of groups, the evaluation of students' performance, etc. Among them, the selection of resources is very time-consuming and selecting a suitable reading material for each student is very difficult for ordinary leachers. This is partly because most commercially available resources in Japan do not give grade levels for which they are suitable. Readability indices, which have a long history of research since the 1920s in the United States, may predict subjectively the relative difficulty of reading materials.

The ultimate purpose of this series of research is io develop a readability formula or index which will predict the reading difficulty of English materials as a foreign language, and if possible, a listenability formula.

Klare (1974-75) concludes after reviewing readability studies over the years, among many other variables, "the word or semantic variable is consistently more highly predictive than the sentence or syntactic variable when each is considered singly," and "using a list of familiar words appears to give a slightly more predictive index than counting word lengths, probably because length is a (secondary) reflection of familiarity.

Therefore, this study did not intend to develop a new formula, but it was designed to determine whether KIYO SCORE, percentage of hard words outside a new word list (Kiyokawa, 1980), will predict the readability of a new sample of reading materials after statistical analyses (in terms of correlations with two criterion). The word list is a combined word list based on three of the latest research studies: Kucera and Francis (1967) and two other data. It is also a graded list in three stages.

We should always bear in mind that readability formulas or indices do not measure all the variables of reading materials. Dale and Chall (1956) pointed out what the indices do not measure-that is, the organization of the material, conceptual difficulties in relatively common and short words, the nature of the content and the reader's interest in it, because it seems they cannot be measured reliably.

5. Hideo KIYOKAWA, Assistant Professor of English at Wayo Women's University, earned the M.A. in Education at the International Christian University, Tokyo.

\section{KLOPF, Donald W. (ISHII, Satoshi)}

572. University of Hawaii, Honolulu, Hawaii, USA

3. 27.3 - presenter.

4. For abstract see ISHII, Satoshi.

5. Donald W. KLOPF is a Professor and Departmeni Chair, Department of Speech, at the University of Hawaii in Honolulu. 


\section{KOGANEI, Takeo}

58 2. Meiji Gakuin University, Tokyo, Japan

3. FLEAT COMMITTEE: General Affairs

4. (no Abstract)

5. Takeo KOGANEl, is an Assistant Professor at the Meiji Gakuin University Foreign Language Institute.

1. КОнмото, Sutesaburo

59 2. Meiji Gakuin University, Tokyo, Japan.

3. 6- chair; 1 - panelist; 38 - participant; 39 - panelist.

4. (no Abstract)

5. Sutesaburo KOHMOTO, Professor of Linguistics and Language Teaching, is Dean of the Graduate School of English Studies at Meiji Gakuin University. Professor KOHMOTO earned the Doctorate in Education at the University of Michigan, and has published extensively in the fields of linguistics and phonology.

1. KOIKE, lkuo

602 . Keio University, Tokyo, Japan.

3. 29 - presenter.

4. (no Abstract)

5. (no bio info)

1. KOMURA, Mikio

61 2. Osaka Kyoiku University, Osaka, Japan.

3. 20 - chair.

4. (no Abstract)

5. Mikio Komura is an Associate Professor at the Osaka Kyoiku University.

1. KONO, Morio

62. 2. Kobe City University of Foreign Studies, Kobe, Japan

3. 36 - panelist.

4. (no Abstract)

5. Morio KOHNO, a Professor at the Kobe City University of Foreign Studies has edited and authored several books and dictionaries dealing with the teaching of English. Professor Kohno is a member of the FLEAT Projects Committee.

\section{KOYAMA, Shuichi}

63 2. Kansai Medical School, Osaka, Japan.

3. 19.2 - presenter.

A PRACTICAL APPLICATION OF EMG BIOFEEDBACK TO THE TEACHING OF ENGLISH CONSONANTS UNFAMILIAR TO IAPANESE

4. In the present paper EMG biofeedback technique, which has been developed mainly for physical and psychotherapy, was applied to teach the pronunciation of English consonants unfamiliar to Japanese. Electrical activities obtained from the Temporalis, Masseter, Levator labii superioris alaeque nasi, Orbicularis oris, Depressor labii inferioris, 
and Digastricus venter anterior muscles of four English native speakers and four well-trained Japanese indicated the following: (1) Light pouting of the lips during the preparatory period for pronouncing the English / $r$ / sound, (2) Raising of the upper lip from the preparatory period in the pronouncing of the $/ \mathrm{sh} /$ and $/ \mathrm{th} /$ sounds, and finally (3) A downward spreading of the lower lip from the preparatory perior in the pronouncing of the $/ 1 /$ and $/ \mathrm{s} /$ sounds.

The above findings led us to select the Orbicularis cris and Depressor labii inferioris muscles of untrained Japanese subjects for EMG biofeedback training. Surface electrodes were attached to these two muscles. The subjects were provided with visual and auditory feedback of these two muscle activities. Cards of English words were shown as stimuli for speech. It was explained to the subject that the feedback consisted of a tone and that the tone reflected tension in their speech muscles. After half an hour of the biofeedback training, the discharge patterns of the formerly unirained Japanese approached those of native English speakers tested; at the same time, the sounds much improved. As a typical example, a remarkable discharge of the Orbicularis, oris appeared when the /sh/ sound was pronounced by the formerly untrained Japanese subjects; a strong discharge of the Depressor labii inferioris. when the /s/ sound was pronounced by the same subjects. The success of the biofeedback training suggests that it will significantly benefit the teaching of English consonants unfamiliar to Japanese.

5. Shuichi YOKAMA, a lecturer at the Kansai Medical School, earned an M.A. in Speech Communication at Emerson College, Boston, Mass., U.S.A.

\section{KUNIYOSHI, Takeo}

64 2. Chiba University, Japan.

3. \#24 - host.

4. (no Abstract)

5. (no bio info)

\section{KURIYAMA, Shoichi}

65 2. Waseda University, Tokyo, Japan.

3. LLA Chapter Representative

4. (no Abstract)

5. Shoichi KURIYAMA, Executive Secretary of the LLA Kanto Chapter, received the M.A. from Waseda University and is currently Language Lab Director in the School of Commerce, Waseda University.

\section{KURODA, Takashi}

66 2. Otsuma Women's College, Tokyo, Japan.

3. 1 - panelist, 6 - presenter, 7-1 - presenter, 29 - panelist HISTORY OF FOREIGN LANGUAGE EDUCATION AND THE USE OF TECHNOLOGY IN JAPAN

4. Of the European languages, Dutch was the first to be studied. Nagasaki was the only port of entry and through it came Western 
learning via Dutch. With the establishment of the school system in 1872 English was taken up in secondary schools. In some schools French or German was also taught. The method was mainly on the line of grammar and translation until Harold E. Palmer came as linguistic adviser to the Ministry of Education in 1923. He revolutionized English teaching by converting many teachers into oral methodists. After Palmer left, A. S. Hornby continued his reform movement. The war years intervened and foreign language study reached its lowest ebb.

Oral Approach. or Audio-lingual Approach, was introduced after the war from the United States chiefly through Charles C. Fries and W. Freeman Twaddell. This and Palmer's oral method did not differ very much in principle: only in that Oral Approach was based upon American structuralism in linguistics coupled with behaviorism in psychology. The teaching procedures of the approach comprise these steps:

(1) Recognition of the meaning of an utterance

(2) Mimicry-memorization

(3) Variation or pattern drills

(4) Selection or question-answering

It is obvious that much oral practice is needed to attain oral mastery, and that good models are essential. Because of the difference beiween the pupil's mother tongue and the target language an average Japanese is said to require as much as five times more repetition than an European. Hence the role of technology.

The most commonly used technological aids in schools are tape recorders and video tapes. Language laboratories are being t:sed in approximately 13 per cent of about 10,000 lower secondary schools and 18 per cent of about 5,000 upper secondary schools. The ratio of universities and colleges with language laboratories is much higher.

The media for the largest-scale foreign language education arc radio and television. The Japanese Broadcasting Corporation (NHK) has been broadcasting English language courses of different levols by radio since 1925 and television since 1953. More than ten different language courses are being broadcast to schools and homes reqularly each week. Keen students take advantage of them, some by making copies on their own tapes. Some schools and colleges use recordings from the BBC or the Far East Network. Indeed, radio and television are doing an immense service not only to students and teachers but to people from all walks of life.

5. Takashi KURODA, President of the Language Laboratory Association of Japan and of the FLEAT Conference is Professor Emeritus of English at the Tokyo University of Education and a Lecturer at the Ostuma Women's College. Professor KURODA has served as Director of the Modern Language Institute at the Tokyo University of Education and has published extensively in the field of English Language Teaching. 
1. LALLY, Dale V. Jr.

672. Universiy of Louisville, Louisville, Kentucky, USA

3. 1 - panelist, 10 - chair, 21 - chair, 26 - chair, 39 - panelist

4. (no Abstract)

5. Dale V. LALLY Jr., Director of the Arts \& Sciences Learning Laboratory at the University of Louisville, Kentucky, is Editor-in-Chief of the NALLD Journal: Technology and Mediated Instruction and responsible for the publication of the FLEAT program.

\section{LALLY, Doris R.}

68 2. University of Louisville, Louisville, Kentucky, USA

3. NALLD Hospitality Committee Chair

4. (no Abstract)

5. (no bio info)

\section{MACHIDA, Takaya}

69 2. Nagoya Gakuin University, Japan.

3. 23 - Chair

4. (no Abstract)

5. (no bio info)

1. MAHER, John Christopher

70 2. Shimane University of Medicine, Japan

3. 30.4 - presenter.

\section{MACHINE TRANSLATION REVISITED IMPLICATIONS FOR THE TEACHING OF ENGLISH AND TECHNOLOGY}

4. Computer assisted translation promises to become more and more relevant to the field of foreign language education as the need for faster interlingual information exchange increases. Moreover, there are signs that the traditional problem areas of machine translation (MT) - theoretical, mechanical, linguistic - are at last being confronted directly. This is due, to a large extent, to an increasing level of technological competence and a greater realism about what MT can and cannot accomplish. In place of the unbridled enthusiasm of the 1950s and the subsequent disappointments as problems seemed to become more complex and unmanageable, there are signs now of a renewed optimism that this area of information transfer technology (ITT) has a positive future. This and other developments in the field have important implications for all those involved in foreign language learning and teaching.

This lecture, therefore, will present a review of recent developments in MT and then discuss some of the linguistic and educational issues involved. Among them: How is MT coping with the 'rules of grammar problem'? What are the principles of word selection in electronic dictionaries? Is MT destined to replace foreign language learningi teaching? Is the search for high-level MT systems a tacit admission that foreign language teaching has been a general failure?

In particular, this lecture will address itself to the possibilities that 
MT holds for the area of Language for Special Purposes (LSP) and especially English for Science and Technology (EST). Three areas will be offered to teachers of EST for consideration and further discussion: First, the possible role of terminology database in technical reading. Second, the implications of the development of more interactivetranslation computers for technical writing. Third, the syntactical suitability of scientific English for machine assisted translation.

The theme of this lecture may be of general interest to all language teachers and especially those involved in translation or teaching English for scientific purposes at the university level.

5. (no bio info)

1. MAJHANOVICH, Suzanne

712 . University of Windsor, Ontario, Canada

3. $\mathbf{1 2 . 1}$ - presenter.

\section{A SYSTEMATIC APPROACH TO THE DEVELOPMENT OF AURAL SKILLS}

This presentation discusses auditory comprehension as a skill which must be developed in second language learners if communicative competence is to be achieved. The author coniends that while most programs treat the rudimentary aspects of listening skills with rather mechanical drills, exercises to develop this skill in more advanced stages are usually not included. S. Majhanovich surmises that the reason for this lies in the fact that authors have most probably not analysed the process of listening and tend to take for granted that this receptive skill will develop by itself as the learner progresses through the program. However, with the trend toward the development of communicative competence as a major aim of second language programs, the need for more sophisticated listening activities than have previously been used becomes obvious.

Analysis of how listening comprehension takes place reveals that the learner/listener goes through an active cognitive process in exercises and activities can be designed to help learners grasp specific information from messages, and other activities lead learners to a point where they are capable of understanding globally what they have heard.

The author stresses the practical elements that teachers can use to aid their students in developing aural comprehension. She includes a series of exercises and activities which can be undertaken in classroom situations to develop both specific and global listening comprehension. She describes how teachers in addition to regular taped exercises can make use of the telephone, radio, television and teaching kits and films in the listening program.

This presentation is geared to teachers of English as a second language but has practical application for teachers of other second languages.

5. Dr. Suzanne MAJHANOVICH is an Associate Professor on the faculty of the University of Windsor, in the field of listening skills. She is the 
co-author of the Ontario Ministry of Education French Guidelines and is the author of a three book Intermediate French textbood series.

\section{MANDELSON, Leonore $R$.}

72 2. Central School, Freeport, New York, USA

3. 13.2 - preseriter.

\section{TEST PERFORMANCE ON A VERBAL LEARNING TASK}

\section{AS A FUNCTION OF ANXIETY-AROUSING TESTING INSTRUCTIONS}

4. The relationship between what a pupil does and what he is capable of doing has long concerned the foreign language teacher. At all levels - elementary, high school, and college - a sizable proportion of students enrolled in foreign language classes has substantially greater difficulty in foreign language study than in other subjects. Continuing efforts to find and describe causes of poor performance by examining the abilities, motivation, attitudes, and personality of foreign language underachievers have produced conflicting and inconclusive results.

In the foreign-language classroom, tests are used to judge capacity to learn, to guide teaching, to check learning progress, to discover learning difficulties, to improve teaching techniques, and to assess teaching effectiveness; but the teacher often finds himself stymied in using tests for these avowed purposes because he suspects that other factors, largely hidden, are interfering with the testing goals. A foreignlanguage testing situation is one of particular anxiety for many individuals and may well affect test performance despite careful advance preparation. Anxiety about tests and test-like situations in the foreign language classroom may, therefore, be fruitfully investigated for possible clues as to why some students achieve better than others of the same aptitude and background.

It may be hypothesized that underachievement in foreign language classes is, in part, a function of pupils' anxiey in test situations. That is, it would seem that pupils who suffer from a debilitating degree of test anxiety also tend to achieve less than their potential capacity and aptitude would indicate they should, despite the generally presumed positive correlation between general achievement and both aptitude and intelligence. Thus, the purpose of this study was to clarify some of the dynamics of test anxiety in the foreign-language classroom: to evaluate the effect of different test instructors (calculated to arouse or reduce test anxiety) on the test performance of foreign language puplis.

A verbal learning task comprised of Japanese words and a criterion test based on he learning ask were adminisered to ninety-six students randomly assigned to three groups each composed of sixteen students of each sex.

The students were randomly selected from approximately 300 firstlevel foreign language students of a public junior high school. The sample consisted of ninety-six seventh graders (evenly divided as to 
sex), all of whom were white, of predominantly the middle economic level, and with a median age of 11 or 12.

In summary, although no differences were found in test performance as a result of testing directions in the sample as a whole, the differences become considerably more pronounced when mean differences for cells within the three groups are examined. Rather startling differences in performance are readily apparent between groups and between sexes. These results indicate the anxiety-provoking situation had a differential effect on the test performance of the sexes debilitating for boys and facilitating for girls. Furthermore, some degree of anxiety appears to have produced a beneficial effect on achievement scores for girls, whereas the creation of a "relaxed" atmosphere appears to have had a depressing effect on scores of girls when compared with those of the control group.

5. Dr. Leonore R. MANDELSON was born in Vienna, Austria, and grew up in Mexico and California. She is a graduate of Mexico City College (A.A.), the University of Missouri (B.J.), the State University of New York at Geneseo (M.S. in Library and Information Science), and the University of Rochester (M.A. and Ed.D.). Her articles have appeared in Hispania, The Journal of Educational Research, and The Christian Science Monitor. In addition to extensive travel and studies in Europe and Latin America, Dr. MANDELSON has done extensive translation, interpretation, and narration for a wide variety of business firms, as well as for the Inter-American Bar Association.

\section{MATSUMOTO, Seiya}

732. Nanzan Junior College, Nagoya, Japan.

3. FLEAT Advertising Committee.

4. (no Abstract)

5. Seiya MATSUMOTO is an Assistant Professor of English in the Department of English at the Nanzan Junior College.

1. MATSUMOTO, Takashi [FUJISAKI, Masayuki (17); GOTO Shuji (18); KIMURA, Yoichi (51); YAMADA, Akitoshi (142)]

74 2. Matsushita Communications, Acoustic Research Laboratory, Japan.

3. 30.1 - presenter.

4. For Abstract see FUJISAKI, Masayuki.

5. (no bio info)

1. MATSUYA, Hideaki [OGAWA, Tadao (94) \& OZAWA, Nobuharu (99)]

75 2. Tokai University, Kanagawa, Japan.

3. 23.3 - presenter(s).

THE LANGUAGE LAB AT TOIKA UNIVERSITY

4. Hideaki MATSUY, Tadao OGAWA and Nobuharu OZAWA will give a combined presentation on the language laboratory at Tokai University, including its history, current capabilities and future prospects for language laboratories from a technical point of view.

5. (no bio infol 


\section{MCANDREW, Alex}

76 2. University of Sydney, Australia

3. 26.4 - presenter.

\section{TAMING THE TERRORS OF TECHNOLOGY}

4. The introduction of technology into our daily lives has undoubtedly improved the quality of life in many aspects, yet, it has likewise brought problems: less personalized communication, disintegrated family life, phobias of machines, fears of invasion of privacy and of political manipulation. As with every new development, however, solutions to problems must be found by constant evaluation, review and adjustment.

In education technology, initially associated with the population explosion and applied to deal with massive groups, often increased the loneliness of the "student cork in an endless ocean". The language or learning laboratory, however, brought positive hope for the full self-realization of the individual. The finest language learning aid ever produced has not been without its opponents. Initial euphoria was followed not only by disillusionment and technophobia, but also by prejudical cries of useless gadgetry. Gradual review and experience has brought adjustments and improvements: a realization that the large "fab labs" of the early years were a mistake, that "small is beautiful" and practical for teachers and student alike; that machines should be designed not by the technocrats alone, but according to the aims and needs of the users, both teachers and students; a recognition that the prioriy given to the three basic elements in any learning laboratory, i.e. hardware, software and "humanware", should be changed, that the human factor should dominate, that programmes be improved and that hardware become less terrifying, more flexible and humane.

The humanization and softening of the technology must vary according to the needs of its users in different institutions and different countries. How it has been achicved in the Language Study Centre of the University of Sydney. Austrtlia, will be illustrated by coloured slides.

5. Alex MCANDREW is the Director of the Language Study Centre at the University of Sydney (Australia).

\section{MCGREGOR, Karen}

77 2. University of Louisville, Louisville, Kentucky, USA

3. NALLD Program-Staff Writer.

4. (no Abstract)

5. Karen MCGREGOR, a graduate student from Austialia and currently enrolled in the School of Education at the University of Louisville, wrote the section on TOKYO-WHAT TO DO AND HOW TO DO IT.

\section{MIKI, Eiichi}

78 2. Hyogo Prefectural Board of Education, Japan.

3. 26 - chair. 
4. (no Abstract)

5. Mr. Eiichi MIKI, a graduate of the Tokyo University of Education, is a supervisor with the Hyogo Prefectural Board of Education.

\section{MISONO, Kazuo}

79 2. Kanto Gakuin University, Japan

3. FLEAT Advertising Committee.

4. (no Abstract)

5. Kazuo MISONO, a Professor at Kanto Gakuin University, received the M.A. from Maiji Gakuin University, Tokyo, Japan.

\section{MIYAHARA, Fumio}

80 2. Kyushu University, Fukuoka, Japan.

3. 19 - chair.

4. (no Abstract)

5. Fumio MIYAHARA, Associate Professor of English at Kyushu University, has published extensively in the field of English Linguistics and the Teaching of English.

\section{MIZUMACHI, Isao}

812. Tokai University, Atsugi, Japan.

3. 30.3 - presenter.

\section{TELP-CAI SYSTEM FOR ENGLISH TEACHING}

4. TELP is the acronym for Tokai English Language Program. The name was given to the courseware produced for a project team organized by Tokyo Junior College of Tokai University in 1978. Team members were drawn from the university, the junior colleges and the attached schools. The team prepared instructional materials in drill and practice mode and also designed a stand-alone microcomputer system with audio-visual and input capabilities.

In 1979, 30 machine sets were installed at the college to be used for English classes. The subsequent review of the materials and the system led the team to the conclusion that CAl (Computer-AssistedInstruction) should be developed further. Since then, TELP courseware writers and engineers have been engaged in building a new system which should be tested this spring.

This is a report by a courseware writer, who describes what the TELP-CAl system can do, although the project is still at the halfway stage.

5. Mr. Isao MIZUMACHI is an Associate Professor at Tokai University.

\section{NAGARA, Susumu}

82 2. The University of Michigan, Ann Arbor, Michigan, USA

3. 29.3 - presenter.

PRINCIPLES GOVERNING THE NATURAL ACQUISITION OF A SECOND LANGUAGE AND THEIR IMPLICATIONS FOR THE ORGANIZATION OF FOREIGN LANGUAGE TEACHING PROGRAMS

4. Today, the learning of make-shift languages by various ethnic groups in contact is probably one of the few instances of natural second 
language acquisition. In the classroom study of foreign languages, the selection of vocabulary items and grammatical features is dictated by the emphasis of the instructor reflected in the choice of textbooks and in the introduction of items to be studied.

In my presentation, I will first describe, according to Tagmemic hierarchy, the process Japanese immigrants took in becoming proficient in Picaeon English in Hawaii. Then, I will verify that three basic principles govern their acquisition of the syntax of this type of make-shift language. They are, (1) the neutralization of paradigmatic contrasts as observed in the neutralization of tense markings in verbs and the neutralization of number markings in nouns, (2) the dominance of unmarked forms as observed in the dominance of the present tense forms of verbs and the dominance of the singular forms of nouns, and (3) the order of syntactic acquisition in accordance with the hierarchy of word-phrase-clause-sentence. The last principle is observable in the fact that most immigrants have acquired some English syntactic features on the clause level but not on the sentence level constructions.

These three principles are significant in developing techniques and programs in foreign language teaching. For example, the neutralization of paradigmatic contrasts illustrates the importance of the development of the learners' psychological awareness of paradigmatic contrasts, especially when the specific paradigmatic contrasts do not exist in their native system. The dominance of unmarked forms reminds us of the necessity of emphasizing the inclusion of additional practice on marked forms in autonomous programmed courses for $L L$ and other learning aids. The importance of syntactic hierarchy demonstrates the necessity of the shift in psychological conceptualization in foreign language learning programs.

5. (no bio info)

1. NAKA IIMA, Fumio

83 2. Tokyo University, Japan

3. FLEAT Advisor

4. (no Abstract)

5. Fimio NAKAJIMA, is Professor Emeritus and received his Doctorate from Tokyo University.

1. NAKAMURA, Taeko [INAGAKI, Shigeko (33) \& ISHIDA, Toshiko (36)]

84 2. International Christian University, Tokyo, Japan

3. 28.1 - presenter.

4. For Abstract see INAGAKI, Shigeko.

5. (no bio info)

1. NAKAYAMA, Kaneyoshi

85 2. Kato Gakuin Language Institute, Japan. 
3. 1-panelist; 39 - panelist.

4. (no Abstract)

5. (no bio info)

\section{NAKAYAMA, Yukihiro}

86 2. Kobe YMCA College, Japan

3. 27.2 - presenter.

NON-NATIVE "ENGLISHES": PROBLEMS AND CAUSES

4 It has been quite some time since English was said to function frequently as an international language. As international interactions have increased in number, the role of English has become more important not only in political-economic settings but also at international conferences, academic conventions, etc. It seems to be practically impossible to deny the fact that English is used on a global scale.

English as an international language is now used in three different types of interactions: (1) English native speakers of different countries interacting with one another, (2) non-native speakers interacting with native speakers, and (3) non-native speakers of different non-English speaking countries interacting with one another. In recent years there has been a remarkable increase in this third category. The varieties of "English" used by non-native speakers, particularly in this third type of interaction, are here called non-native "Englishes." As a result, new problems have arisen.

Realizing these problems, some directors of language training programs in the business sector have begun to cope with them. U'nfortunately these people are exceptional. Most people in English language education do not even realize the problems that non-native "Englishes" pose. Furthermore, there has not been much academic discussion on these problems; there has scarecely been any empirical research at all.

Specifically, these problems are (1) some non-native speakers of country $X$ can not understand "Englishes" spoken or written by nonnative speakers of countries $Y$ or $Z$; and (2) some non-native speakers of country $X$ can not speak or write "an English" that non-native speakers of countries $Y$ or $Z$ understand.

The major cause of this lack of communication seems to be that English has been taught to non-native speakers with the assumption that the lexis, grammar and pronunciation of English are those of an idealized American or Briton from an idealized American or British culture. This type of language education has not prepared nonnative speakers for the third category of interaction mentioned above. In this presentation, we will look into the problems and causes through a review of the literature and discuss some possible solutions to the problems.

5. With teaching experience in Japan and the USA, Yukihiro NAKAYAMA was recently a Professional Associate at the Culture Learning Institute, East-West Center, Hawaii. He is presently with the Kobe YMCA 
College. He is also a freelance writer, and has authored/co-authored several tape texts, one of which is Birdree English Conversation Series: Introductory Course. (Co-authored, Osaka: Senshukai Publishing Co., Ltd., 1975).

\section{NISHIMOTO, Mitoji}

87 2. Japan Radio/TV Education Association, Tokyo, Japan

3. FLEAT Advisor.

4. (no Abstract)

5. Mitoji NISHIMOTO, President of the Japan Radio/TV Education Association, received the Doctorate in Education from Tokyo University. Dr. NISHIMOTO has published extensively in the field of educational broadcasting.

\section{NIWA, Yoshinobu}

88 2. Nagoya University, Japan.

3. 22 - chair; 1 - panelist; 22 - chair; 39 - panelist.

4. (no Abstract)

5. Professor Yoshinobu NIWA, who earned the Doctorate at Nagoya University, is the chief producer of language lab educational and visual aids in the Language Center at Nagoya University.

1. NOMURA, Kazuhiro [AZUMA. Junichi (10) \& YAMANE, Shigeru (145)]

89 2. Tezukayama Gakuin Junior College, Japan

3. 22.3 - preseñter.

4. For Abstract see AZUMA, Junichi.

5. Kazuhiro NOMURA, A Lecturer at the Tezukayama Gakuin Junior College, received the M.A. at the Kobe City University of Foreign Studies. He is also the co-author of a text on English grammar.

1. NUKII, Takanori [YAMADA, Hidesaburo (143) \& UENO, Takao (135]

90 2. Rakuhoku Senior High School, Kyoto, Japan

3. 22.1 - presenter.

\section{TEACHING ENGLISH THROUGH VIDEO TAPES AT} THE SENIOR HIGH SCHOOL LEVEL

4. Heidesaburo YAMADA will describe an advanced language lab technique for developing oral comprehension and verbal fluency among Japanese senior high school students. In the language laboratory at Rakuhoku Senior High School in Kyoto, each booth is equipped for both audio and video programs. The staff uses in-house produced video tapes of native speakers of English. In addition, a character generator is used to superimpose the English or Japanese text onto the videotape. Separate audio tapes are also produced, a few of which have special pauses for slow learners. This entire approach is referred to locally as "multiplex language lab".

5. (no bio info) 


\section{OBatA, Masatoshi}

912. Tenri University, Japan

3. 35 - recorder.

4. (no Abstract)

5. (no bio info)

1. OCHIAI, Jiro

92 2. Fuchu Higashi Senior High School, Tokyo, Japan.

3. 1 - panelist; 39 - panelist.

4. (no Abstract)

5. Jiro OCHIAI is a member of the FLEAT Program Committee.

1. ODA, Yukinobu

93 2. Doshisha Women's College, Kyoto, Japan.

3. 35 - chair.

4. (no Abstract)

5. Yukinobu ODA, a Professor at Doshisha University, has taught English for over 30 years at both the secondary and college levels.

1. OGAWA, Tadao. [MATSUYA, Hideaki (75) \& OZAWA, Nobuharu (99)]

942. Tokai University, Kanagawa, Japan.

3. 23.3 - presenter.

4. For abstract see MATSUYA, Hideaki

5. (no bio info)

95 1. OGAWA, Yoshio

3. FLEAT Adviser.

1. OINOUE, Shigeru

96 2. Meiji Gakuin University, Tokyo, Japan

3. LLA Chapter Representative.

4. (no Abstract)

5. Shigeru OINOUE, Professor of English and Director of the Foreign Language Institute at Meiji Gakuin University, received an M.A. degree in Teaching English as a Foreign Language from the University of Michigan.

1. OSUGI, Masaaki

97 2. Seisen Women's College, Tokyo, Japan

3. FLEAT Hotels \& Tours Committee.

4. (no Abstract)

5. Masaaki OSUGI, an Assistant Professor at the Seisen Women's College, received the M.A. from the Meiji Gakuin University.

1. OYAGI, Hiroto

98 2. Tokyo Denki University, Tokyo, Japan

3. FLEAT Fund Raising Committee. 
4. (no Abstract)

5. Hiroto OYAGI, an Assistant Professor at the Tokyo Denki University, is a member of the FLEAT fund raising committee.

1. OZAWA, Nobuharu IMATSUYA, Hideaki (75) \& OGAWA, Tadao (94)]

99 2. Tokai University, Kanagawa, Japan

3. 23.3 - presenter.

4. For abstract see MATSUYA, Hideaki

5. Nobuharu OZAWA is Director of the Technical Section in the Language Laboratory at Tokai University.

1. PALLISTER, Janis $L$.

100 2. Bowling Green State University, Bowling Green, Ohio, USA

3. 13.3 - presenter.

THE CULTURE TRACK: A VIABLE ALTERNATIVE TO THE FOUR SKILL. TRACK?

4. In the past several years the department of Romance Languages of Bowling Green State University (Ohio) has been including in its curriculum for the language requirement the so-called culture track, which has offered language training at the passive level only, while spending most class-time on readings and discussions regarding the civilization of the respective country and supporting these activities with audio-visual media. The present paper will discuss the rationale, the perceived benefits and the known impediments of this approach, based on seven years of experimentation with various methods, textbooks, instructional materials and class sizes and then will make a recommendation to conference participants regarding the adoption of this particular alternate to the four-skill rack.

5. Dr. Janis L. PALLISTER, Professor of Romance Languages at Bowling Green State University (Ohio), received the Doctorate from the University of Minnesota. She is a prolific writer, having authered numerous books, manuals, monographs, articles and poetry in English, French and Spanish.

1. PRAWER, Flornece Helen

1012 . Central School, Freeport N.Y., USA.

3. 13.1 - presenter.

THE SELF-CONCEPT AS RELATED TO ACHIEVEMENT IN FOREIGN LANGUAGE STUDY

4. Research in this century provides ample evidence of the importance of personality variables in academic performance. Since students do not always achieve in accordance with their intellectual potential, curricular modification has been a frequent recourse. It would seem appropriate to examine the role of the student, specifically the selfconcept, which has been exploded in various academic areas but not explicityly in foreign language achievement. Dr. PRAWER conducted a study to investigate the relationship between the self-concept of 
ability as a foreign language student (SCFL) and each of the four variables: gender, grade point average, intelligence quota, and foreign language grade. The results indicate that the enhancement of the SCFL may improve not only the student's foreign language achievement, but also result in a general improvement in self-concept.

5. Dr. Florence H. PRAWER received the Doctorate in French from Columbia University (New York). She has laught Spanish and French and the secondary and university levels. Her publications include The Self Concept as Related to Achievement in Foreign Language Study which appeared in THE FOREIGN LANGUAGE TEACHER. Dr. PRAWER has been active in translation, interpretation, and narration work in French and Spanish. She travels extensively in Europe and Latin America.

\section{REIMERS, Theresia}

1022. Hollins College, Roanoke, Virginia, USA

3. $\mathbf{1 0 . 3}$ - presenter; 22 - chair.

THE USE OF VIDEO IN ELEMENTARY LANGUAGE INSTRUCTION

4. Four topics will be discussed briefly with video examples: 1) commercially prepared materials currently available. Of this material, little is matched to specific texts. Some video tapes do come with extensive written materials for student use and suggestions for teachers (Guten Tag, Wie geht's). These are usually quite expensive. German Educational TV Network offers excellent material from German news broadcasts with narration on both beginning and intermediate levels. Texts and vocabulary and suggestions for use are provided. Some PBS programs offer useful material, but here there is the problem of copyright.

2) Materials you develop yourself are likely to be more useful, but the process is quite time consuming: e.g., record a cartoon program, preferably with much action and minimal dialogue, elicit from the students simple dialogue (not translation) and narrative to fit the action, develop a final script from their corrected versions and have them dub it on the tape.

3) Since many students tend to be self-conscious before a camera, especially when speaking a foreign language, the use of puppets to play simple scenes, especially fairy tales, work well. They enjoy playing with the puppets (and can see what they are doing in the monitor) and lose themselves in their parts. Use of puppets also requires minimal space for staging. A projected backgıound can set the mood; with the use of a zoom lens, attention is concentrated on the puppets and minimal setting is required. (video example)

4) Perhaps the greatest challenge is the use of video to teach grammar; less for drill (the computer can do that) than to make clear through visual images concepts which often confuse students: e.g., the use of prepositions in German: Die Katze springt auf den Tisch; die Katze sitzt auf dem Tisch. The use of animation rather than live actors here again simplifies production, requires limited space, and, most im- 
portant, gives you complete control over the image; you show exactly what you want the student to see and no more; there are no extraneous details to distract his attention. Professor REIMERS will use a videotaped exerpts to illustrate various subthemes in her presentation.

5. Dr. Theresia REIMERS, Chair of the Department of Modern Languages at Hollins College, Virginia, is Professor of German and Director of the Language Laboratory. After receiving the Doctorate from Stanford University, she taught German at Stanford, at the Institute of European Studies in Vienna, Austria, and at the University of Hawaii. Her reviews of operatic performances and articles on the staging of Wagner's works have appeared in German and British periodicals.

\section{RICHARDSON, Charles}

103 2. Ohio University, Athens, Ohio, USA

3. 1-panelist; 39 - panelist; 11.3 - presenter; 30 - chair. TRAINING THE LANCUAGE LAB DIRECTOR

4. This presentation will explore the training of the language laboratory director. It will be directed not only at future lab directors, but also include suggestions for current lab directors, who wish to expand their professional horizons. Three professional areas will be examined: 1) mechanical/electronic skills, 2) administrative ability, and 31 curriculum materials development. Each topic will be dealt with from the standpoint of training an individual or training students as part of an integrated program. Finally, the need for the profession to establish guidelines for certification will be discussed.

5. Mr. Charles P. RICHARDSON received the M.A. from Ohio University, where he is currently the Director of the Language Laboratories and Methods Instructor. Mr. RICHARDSON was the Editor of the NALLD Journal from 1969-79 and remains Director of the NALI.D Publications Center.

\section{RIVERS, Wilga}

1042 . Harvard University, Cambridge, Massachusetts, USA.

3. 12- chair; 25 - presenter; 1 - panelist.

\section{UNDERSTANDING THE LEARNER IN THE LANGUAGE LAB}

4. Much research and money has been poured into equipment since language laboratories first burst onto the language learning scene. There was at first great optimism that sludents would now learn languages with an ease and rapidity never observed in conventional classroom situations. Unfortunately, in many areas students voted against laboratories with yawns and sighs. Technological wonders cannot assist learning without effective courseware, that is, a carefully designed and executed language learning sequence that provides authentic language materials which are interesting enough to retain the students' attention and encourage preserverance. We must understand how students learn languages, appreciate what they need to learn to achieve their objectives in undertaking language learning, and provide materials which bridge the gap between the two. 
5. Wilga M. RIVERS is Professor of Romance Languages and Coordinator of Language Instruction in the Romance Languages at Harvard University, Cambridge, Massachusetts. In addition to coordinating and developing language instruction in French, Spanish, Italian and Portugese, Professor RIVERS also supervises the training of teaching fellows in these languages. She has had extensive experience as a high school teacher of French and English, in student teacher supervision, in the design and organization of high school terminal and university entrance examinations, and as coordinator of information on language laboratories and language teaching for the Australian and New Zealand universities. She has taught French and/or English in the United States, Australia, France, England, India and Japan. She has lectured and made presentations throughout the world. Included among her many publications are: The Psychologist and the Foreign Language Teacher, Teaching Foreign Language Skills, Changing Patterns in Foreign Language Programs and Speaking in Many Tongues. Professor RIVERS has had over forty articles published in such periodicals as The Foreign Language Annals, The Modern Language Journal, English Teaching Forum, The Canadian Modern Language Review, TESOL Quarterly, Language Learning and The Georgetown University Roundtable Monographs. Several of the above cited books either have been or are currently being translated into Japanese.

1. SAITO, Hiroshi

105 2. Meiji Gakuin University, Tokyo, Japan.

3. 21.2 - presenter.

\section{A PROPOSITION FOR THE EFFECTIVE USE OF THE LANGUAGE LABORATORY}

4. Although there are various ways of using the language laboratory in teaching a foreign language, its greatest effectiveness comes in the first three of the following five steps of language learning: 1) auditory observation, 2) oral imitation, 3) catenizing, 4) semanticizing, and 5) composition by analogy. The fundamental purposes of the language lab are to provide regular practice in listening to models, in imitating these models and in memorizing patterns through repetition. In the lab, students are ideally able to listen to models of native speech, and imitate those models repeatedly while progressively correcting and improving their oral and aural abilities.

This ideal is often not achieved, however, because many times students who are in the laboratory reinforce their mistakes. For many it is difficult to detect defects in articulation and inonation without proper guidance. Without direction, they may continue to accent wrong syllables and slur others while at the same time being convinced that they are accurately repeating what was said on the tape. Even when they realize their difficulties, they often do not know what to do about them.

Inspired by the systematic approaches of piano instruction and also of a booklet on typing, I have designed a one-year language course 
intended to make more effective use of L.L. equipment. In light of past deficiencies, I would like to describe and propose the necessity of such a course, explaining the ideas 1 have in mind for implementing it, including what kind of exercises should be given in the Pre-lab, Lab, and Post-lab periods.

I invite critical comments as well as constructive suggestions from the participants.

5. Hiroshi SAITO, a Professor at Meiji Gakuin University, has authored two books on the teaching of English.

1. SAITO, Yasuhiro

3. FLEAT Planning Committee.

107.1. SATO, Hajime

3. FLEAT Facilities Committee.

1. SATO, Kazuo

108 2. Nanzan Junior College, Nagoya, Japan.

3. FLEAT Auditing Committee.

4. (no Abstract)

5. Kazuo SATO is Director of the English Department at Nanzan Junior College.

1. SATO, Toyoko

109 2. Meinohama Junior High School, Fukuoka, Japan.

3. 26.1 - presenter; 31 - recorder.

4. (no Abstract)

5. Toyko SATO, an English teacher at Meinohama Junior High School, graduated from Fukuoka Women's University.

1. SATO, Yasushi

110 2. Meiji Gakuin University, Tokyo, Japan

3. FLEAT Overseas Relations Office; 31 - recorder.

4. (no Abstract)

5. Yasushi SATO is an Assistant Professor of English at the Meiji Gakuin University.

1. SAWAMURA, Fumio

1112 . Sonoda Women's University, Kobe, Japan.

3. 29 - chair.

4. (no Abstract)

5. Mr. Fumio SAWAMURA, a graduate of Kobe University, is a teaching consultant for the Hyogo Prefectural Board of Education.

1. SEKIYA, Teruo

1122. Sendai Senior High School, Japan

3. 23.2 - presenter.

AN EXPERIMENTAL STUDY OF RAPID READING

MAKING EFFECTIVE USE OF A VTR

4. When one is teaching a foreign language-especially English, the primary target of most Japanese, the characteristic defferences between 
the two languages, hieroglyphics and syllabics must be taken into consideration. The reason why Japanese are able to grasp the mcaning of a Japanese sentence at a glance is not only because they are familiar with Chinese characters, but also because the Chinese characters themselves have a graphic aspect, which makes it possible for the reader to command a wide eye-span. On the other hand, the target language, English, may not be well understood or rapidly read even at an advantage stage of learning without bcing pronounced either consciously or subconsciously.

The main reason we have initiated rapid reading practice in the Language Laboratory is that (1) the students have already had oneyear in the Language Lab and are familiar with English sounds; (2) each booth is equipped with a small television set, which enables the students to watch not only pictures but also smaller letters and words for rapid reading praclice; (3) it is possible to dispense reading materials in a limited time from the master console to each booth; (4) it is also easy to evaluate the learners' progress by using a response analyzer attached to the master console.

The details of a study carried out to determine the effectiveness in using a videotape recorder in the language laboratory to leach speed reading of English to Japanese high school students will be discussed during this presentation.

5. (no bio info)

1. SHEEHAN, Joseph

1132 . University of Houston, Houston, Texas, USA

3. 1-panelist; 6 - presenter; 39 - panelist.

4. (no Abstract)

5. Joseph H. SHEEHAN, President of the National Association of Learning Laboratory Directors, received the $M$. Ed. from Massachusetts State College in Boston. Professor Sheehan has extensive teaching experience in French, English and Latin and has travelled and taught throughout the world.

\section{SHIIGI, Haruo}

1142. Asia University, Tokyo, Japan.

3. FLEAT Finance Committee.

4. (no Abstract)

5. Haruo SHIIGI is Director of the Language Laboratory at Asia University.

1. SHIKATA, Manji

1152 . Kyoto University High School and Kansai University of Foreign Studies, Japan

3. 23.4 - presenter.

FUSION OF LISTENING COMPREHENSION AND

READING ACTIVITY IN LANGUAGE LABORATORY

4. High school language lab work normally concentrates on lis:ening comprehension and speech production, while classroom activity is 
usually centered on reading comprehension using materials totally separated from the language lab materials. Manji SHIKATA will describe a language lab course designed to integrate normal classroom reading activities with language lab listening comprehension exercises. This course includes three major segments: 1) he viewing of popular television shows recorded onto videotape, 2) listening comprehension exercises based on the television shows, and 3 ) extensive reading in English and Japanese on topics closely related to the television shows.

5. (no bio info)

1. SHIMADA, Masayuki

1 162. Institute of Vocational Training, Tokyo, Japan

3. 30.2 - presenter.

MEDIA AND MATERIALS FOR INDIVIDUAL LANGUAGE INSTRUCTION AND THEIR EDUCATION

4. Masayuki SHIMADA will discuss methods he has developed to permit evaluation of media and other materials as to suitability for individualized language instruction.

5. Mr. Masayuki SHIMADA earned his M.A. at Tokyo's Gakugai College.

1. STRAIN, Jeris

1172. Moza English Language Consultants, Chattanooga, Tennessee, USA

3. 29.1 - presenter.

SELF-INSTRUCTIONAL TEACHING MATERIALS: WHAT AND HOW

4. Given a cassette tape recorder and a moiivated learner, how can language learning be maximized? Students graduating from high schools around the world with an extensive passive knowledge of a foreign language but very weak aural-oral skills are finding to their dismay that further education and employment opportunities are blocked because of their foreign language disabilities. To meet the needs of these individuals, a self-instructional course of instruction must draw from and blend programmed instruction principles, linguistic insights and audio-visual techniques. The purpose of this paper is to highlight the methodology and materials of a selfinstructional English program recently developed along these lines in Egypt for speakers of Arabic.

5. Jeris E. STRAIN, Director of the Moza English Language Consultants in Chattanooga, TN., received the Ed.D. in English Language and Literature from the University of Michigan. $\mathrm{He}$ is the author of several textbooks and has produced television courses in telecommunications and computer science.

\section{STREVENS, Peter}

1182. Bell Educational Trust, Cambridge, England

3. 7.3 - presenter.

4. (no Abstract)

5. Peter STREVENS is the Director of the Bell Educational Trust in Cambridge, England. 


\section{SUZUKI, Hiroshi}

1192 . Tokyo University, Tokyo, Japan.

3. 2 - chair; 30 - chair.

4. (no Abstract)

5. Hiroshi SUZUKI, Associate Professor of English at Tokyo University, earned an M.A. in Linguistics from the University of Michigan.

1. TADOKORO, Nobushige

120 2. Fukuoka University, Fukuoka City, Japan

3. 7.2/3 - chair; 38 - recorder.

4. (no Abstract)

5. Nobushige TADOKORO, is a Professor at Fukuoka University with a B.A. from Kyushu University.

1. TAJIMA, Hiroshi

1212. Kobe City University of Foreign Studies, Kobe, Japan.

3. 1-panelist; 39 - panelist.

4. (no Abstract)

5. Hiroshi TAIIMA is President of the Kobe City University of Foreign Studies.

1. TAKADA, Shideru

1222. Seiwadai Junior High School, Japan

3. 1 - panelist.

4. (no Abstract)

5. (no bio info)

1. TAKAHASHI, Tadashi

123 2. Kinryo Junior High School (MA Candidate at Hyogo University of Education), Japan

3. 23.1 - presenter.

AN EMPIRICAL STUDY OF LISTENING SKILL BUILDING

4. Tadashi TAKAHASHI will describe an experiment, conducted at the junior high school level in Japan, to determine the most efficient means of promoting listening comprehension as the primary skill in foreign language teaching. The results of this experimental study will be presented, based upon three specific elements: 1) pause length, 2) prosodic considerations and 3) visual aids.

5. Tadashi TAKAHASHI is an M.A. candidate at the Hyogo University of Education in the field of Neurolinguistics.

1. TAKAYA, Machida

1242. Nagoya Gakuin University, Nagoya, Japan.

3. 23 - chair.

4. (no Abstract)

5. Takaya MACHIDA, Professor of English at the Nagoya Gakuin University, earned the Ed.M. at Boston University. Professor MACHIDA has published and translated articles in the field of educational technology. 


\section{TAKEFUTA, Yukio}

125 2. Chiba University, Japan.

3. FLEAT Projects Committee.

4. (no Abstract)

5. Yukio TAKEFUTA, Professor of English Linguistics at Chiba University, earned the M.A. and Ph.D. from Ohio State University. He has published extensively in the field of educational technology and is co-editor of Studies on the Language Laboratory, which is being published for the FLEAT Conference.

1. TAKIMOTO, Haruo

1263. FLEAT Treasurer \& Secretary.

4. (no Abstract)

5. Haruo TAKIMOTO earned the B.A. at Meiji Gakuin University.

1. TANAKA, Tatsuo

1272. Japan Ministry of Education.

3. 6- presenter.

4. (no Abstract)

5. Tatsuo TANAKA is the Japanese Minister of Education.

1. TANNER, Jackie

1282. Georgetown University, Washington, D.C., USA

3. NALLD Recording Secretary.

4. (no Abstract)

5. Jackie TANNER, NALLD Recording Secretary, is Director of Language Learning Technology in the School of Languages and Linguistics at Georgetown University. Ms. Tanner earned the M.Ed. at the University of Virginia.

1. TENMA, Michiko

1302 . Tsuda College, Tokyo, Japan.

3. 25 - chair.

4. (no Abstract)

5. Professor Michiko TENMA received her M.A. at the University of Michigan. She translated Teaching Foreign Language Skills by Wilga RIVERS into Japanese.

1. THRASHER, R. H.

1292. International Christian University, Tokyo, Japan.

3. 35 - presenter.

4. (no Abstract)

5. (no bio info)

1. TILL, Graham R. F.

1312. The Linguaphone Institute, London, England

3. 22.2 - presenter.

LEARNING THROUGH PURPOSE-MADE VIDEO

AT THE SENIOR HIGH LEVEL

4. Mr. TILL will begin his presentation with a discussion of the history of 
television in language pedagogy, including broadcast television, CATV, documentaries, off-the-air-recording, time-shift and pre-recorded materials, he will then discuss the attributes of video as a learning medium and exhibit several current techniques using videotaped exerpts. He will then discuss the future implications for multi-media courses, home-made video, interactive video, video discs; computers, along with the problems of international communications and the associated pedagogical considerations.

5. Graham R. F. TILL, Head of the Course Planning and Research Department at the Linguaphone Institute in London, is responsible for the design of home study language courses. He received the M.A. in Applied Linguistics from the University of Essex.

\section{TSUKIYAMA, Hideo}

132 2. Nagoya Junior College, Nagoya, Japan.

3. LLA Chapter Representative; 14 - host.

4. (no Abstract)

5. Hideo TSUKIYAMA is Language Lab Director and Professor at the Nagoya Junior College.

1. TSUNEKI, Kiyoshi

1332. Toyama Medical \& Pharmaceutical University, Toyoma, Japan.

3. 27 - chair.

4. (no Abstract)

5. Kiyoshi TSUNEKI, Professor of English at the Toyama Medical \& Pharmaceutical University, earned the M.A. in Education at the International Christian University in Tokyo.

1. TSUZUKI, Masaki

1342. Kansai Gaidai, Osaka, Japan

3. 6 - recorder; 19.4 - presenter.

HOW TO OVERCOME DIFFICULTIES IN ENGLISH PRONOUNCIATION

4. This paper will deal with the difficulty of learning English pronour:ciation as a function of the fundamental differences between English and Japanese sounds. The presenter will suggest various methods for improving Japanese students' pronunciation of English phonemes through the use of the language laboratory.

5. Masaki TSUZUKI, is an Assistant Professor at the Kansai Gaidai.

1. UENO, Takao [YAMADA, Hidesaburo (143) \& NUKII, Takanori (90)]

1352. Rakuhoku Senior High School, Kyoto, Japan

3. 22.1 - presenter.

4. For Abstract see NUKII, Takanore

5. (no bio info)

1. USAMI, Shozo

1362. NHK Radio \& TV Culture Research Institute, Tokyo, Japan

3. 9-host; 34 - presenter.

4. (no Abstract) 
5. Shozo USAMI is a senior researcher at the NHK Radio \& TV Culture Research Institute.

1. WALSH, Terrence [KITAZAWA, Kaori (55)]

137 2. St. Paul's School, Concord, New Hampshire, USA

3. 1 - panelist; 20 - chair; 28.2 - presenter; 39 - panelist.

4. For Abstract see KITIZAWA, Kaori.

5. Terrence Myrick WALSH, a psychologist and neuroanatomist by training, has had research appointments at MIT and Brown University and has been on the faculty of Dartmouth Medical School and Boston Bureau of Study Council at Harvard, the Academic Counseling Center, and is currently Director of Research at St. Paul's School, Concord, New Hampshire, USA. He has been working on issues of neurolinguistic and psycholinguistic foundations to the acquisition of first and second languages.

\section{WATANABE, Kenkichi}

138 2. Kyushu University, Fukuoka, Japan

3. FLEAT Vice President/Fund Raising; 1 - panelist; 39 - panelist.

4. (no Abstract)

5. Kenkichi WATANABE, Professor Emeritus University, is Head of the Kyushu Chapter of the LLA.

139. WATANABE, Masayoshi

3. FLEAT Fund Raising Committee.

1. WATANABE. Osamu

1402. Komae Senior High School, Tokyo, Japan

3. 17 - host.

4. (no Abstract)

5. Osamu WATANABE, who earned the B.A. from Sophia University in Tokyo, has taught English at the secondary school level for 17 years.

1. WHITE, James D.

1412. Tezukayama Gakuin University, Japan

3. 14 - host; 36 - chair.

4. (no Abstract)

5. James D. WHITE, Ph.D. candidate, Assistant Professor and Director of the Audio Visual Center at Tezukayama Gakuin University, received the M.A. from Tezukayama Gakuin University in 1965.

1. YAMADA, Akitoshi IFUJISAKI, Masayuki (17) GOTO, Shuji (18);

142 KIMURA, Yoichi (51); MATSUMOTO, Takashi (74)]

2. Matsushita Communications, Aoustic Research Laboratory, Japan

3. 0.1 - presenter.

4. For Abstract see FUJISAKI, Masayuki.

5. (no bio info) 
1. YAMADA, Hidesaburo [NUKII, Takanori (90) \& UENO, Takeo (135)]

1432. Rabuhoku Senior High School, Kyoto, Japan

3. 22.2 - presenter.

4. For Abstract see NUKII, Takanori

5. (no bio info)

1. YAMADA, Noboru

1442. Yoshida Senior High School, Shizuoka, Japan.

3. 21.1 - presenter.

GROUP LEARNING IN A LARGE CLASS

4. Noboru YAMADA will discuss the relative merits of group study in teaching a foreign language and particularly the value of peer evaluation.

5. Noboru YAMADA, a graduate of Shizuoka University, received a diploma in the Teaching of English as a Foreign Language from the University of Sydney, Australia. He has also conducted research in the use of short wave programs in the foreign language classroom.

1. YAMANE, Shigeru [AZUMA, Junichi (10) \& NOMURA, Kazuhiro (89)]

1452. Tezukayama Junior College, Japan

3. 22.3 - presenter.

4. For Abstract see AZUMA, Junichi.

5. (no bio info) 


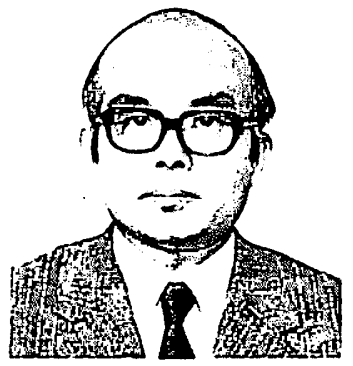

1 Aizu, Yo 34

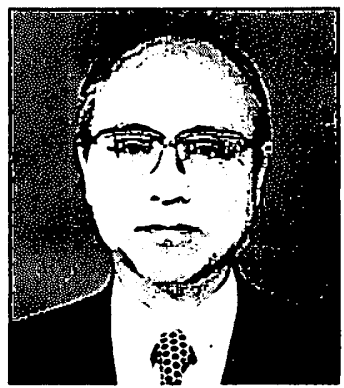

5 Ando, Kenichi 1, 39

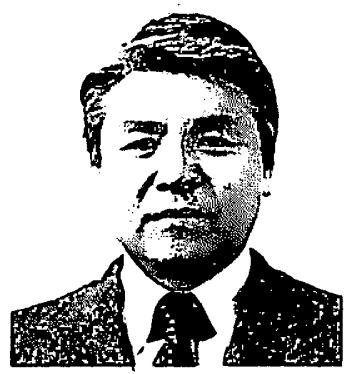

8 Arakawa, Tsuneo

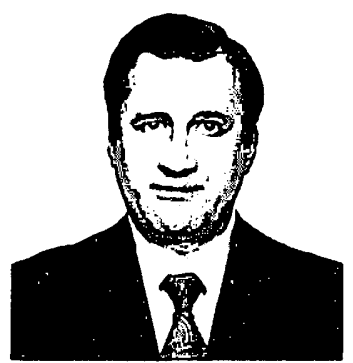

12 Bocaz-Moraga, Sergio 13.4, 29

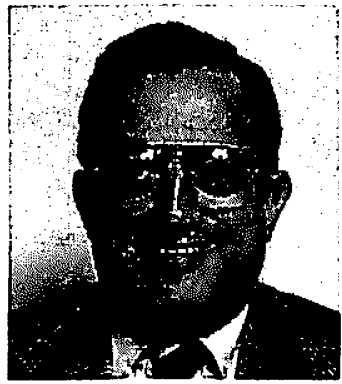

2 Alatis, James E.

$1,27,36,39$

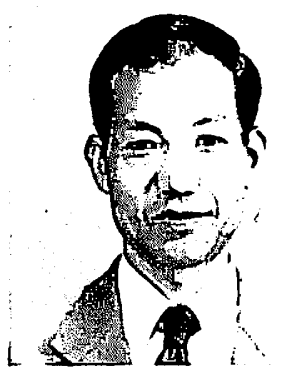

6 Ando, Shoichi 1, 39

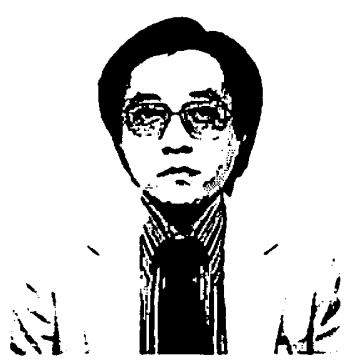

10 Azuma, Junichi 22.3

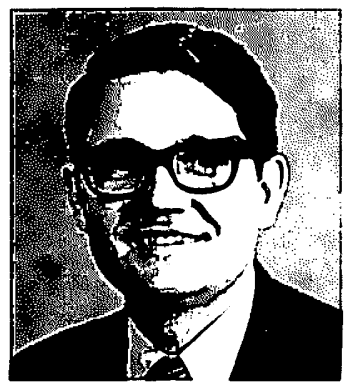

13 Burggraaf, Samuel

$1,31,38,39$

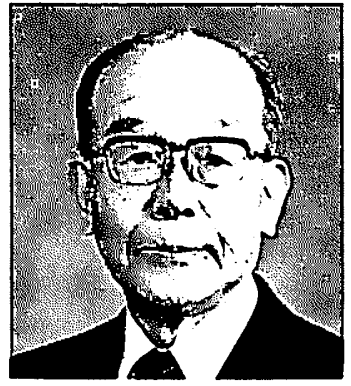

4 Amano, Kazuo 1, 39

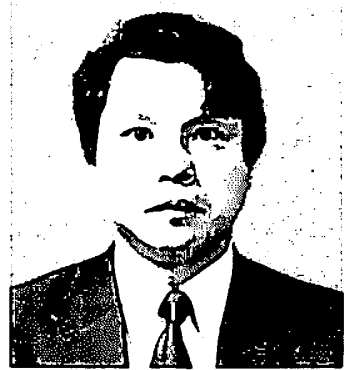

7 Arai, Toshikuni

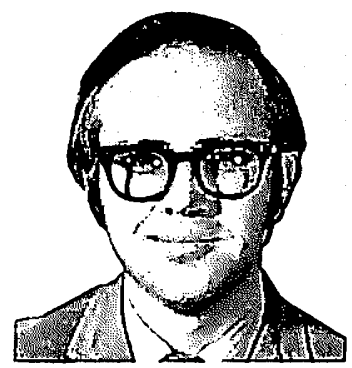

11 Bailey, Leslie F.

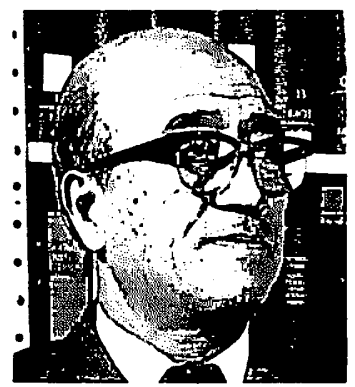

14 Chujo, Sosuke 


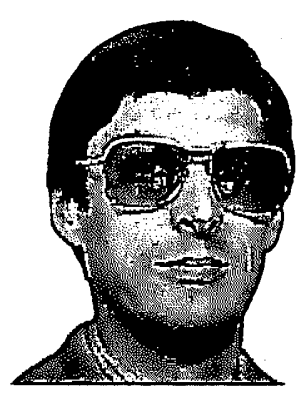

15 Davies, Norman F. 27.4, 36

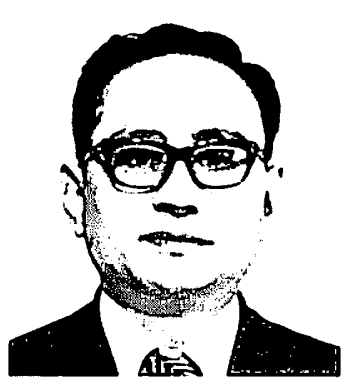

22 Hatanaka, Takami 18

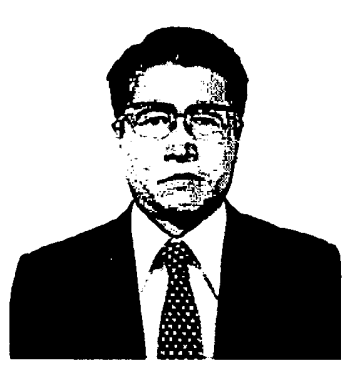

28 Honda, Yoshinori 26.2

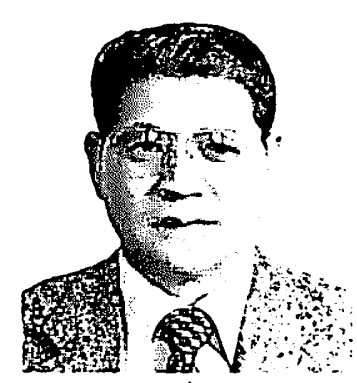

32 Ikeura, Sadahiko

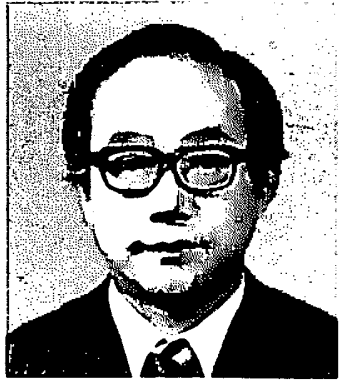

19 Hagiwara, Nathaniel Tsutomu

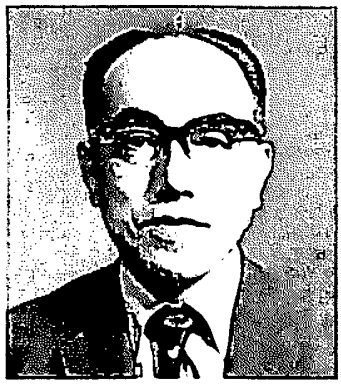

23 Hatori, Hiroyoshi 18, 34

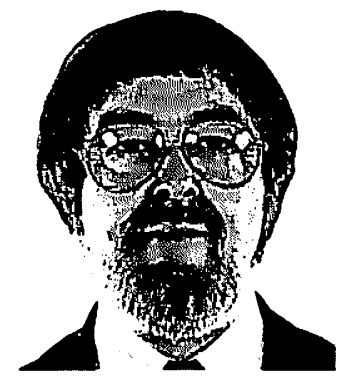

29 Hutchinson, Joseph C. 1, 7.2, 11, 19, 39

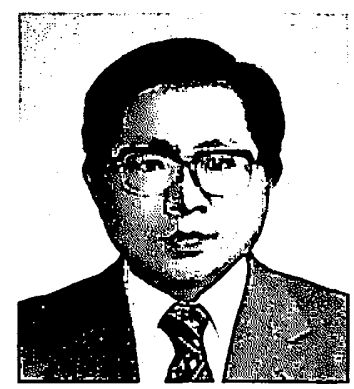

34 Inokuchi, Muneo 26.3

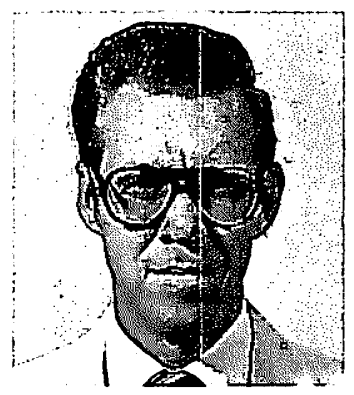

21 Harvey, Edward 2, 11.1, 39

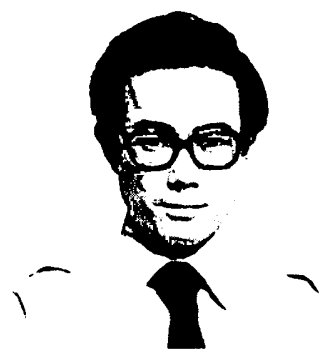

25 Hayase, Mitsuaki 27.1

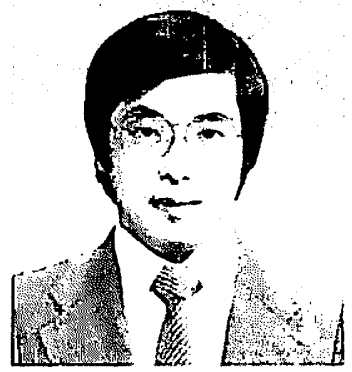

31 Ikari, Yukio 36

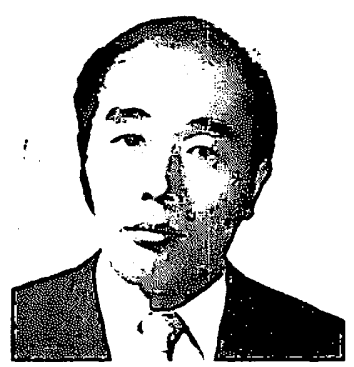

37 Ishii, Satoshi 27.3 


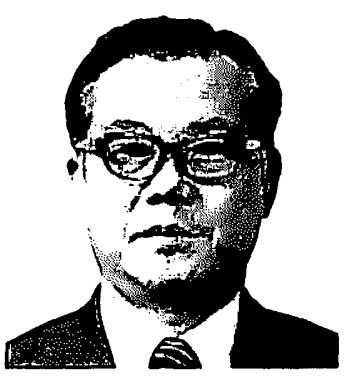

38 Ishikawa, Tatsuro

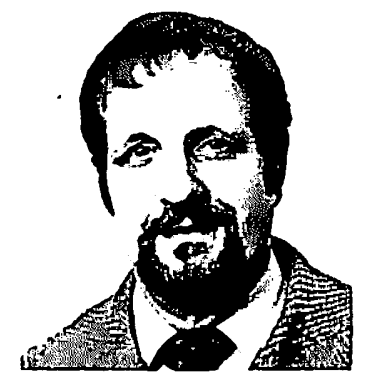

41 James, Eric E. 19.1

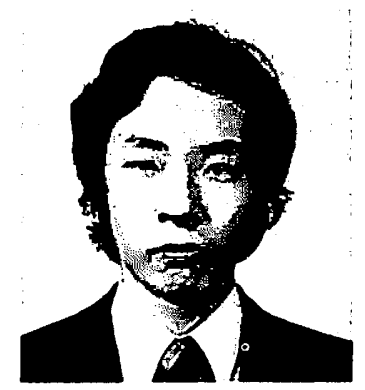

44 Kadota, Shuhei 20.2

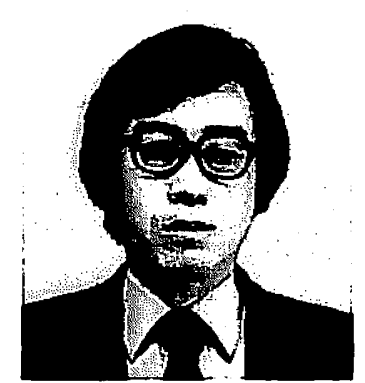

54 Kitao, Kenji 22.4

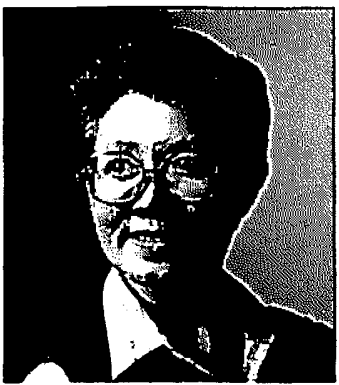

39 Itakura, Takeko 1, 39
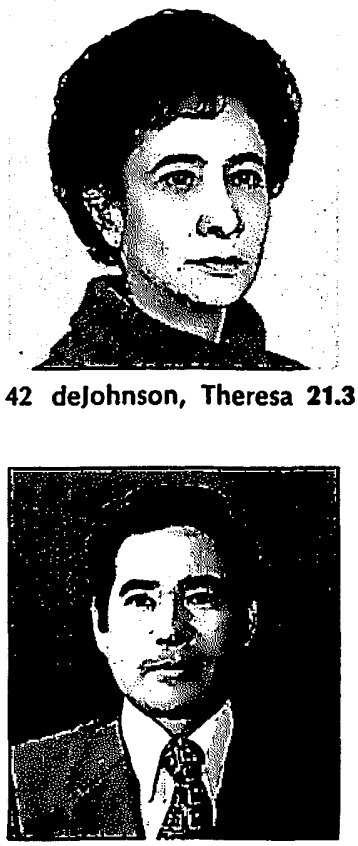

48 Kato, Tadahiko 18, 34

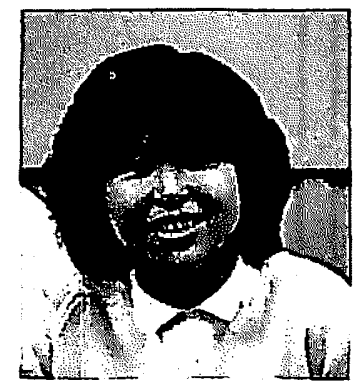

55 Kitizawa, Kaori $\mathbf{2 8 . 2}$

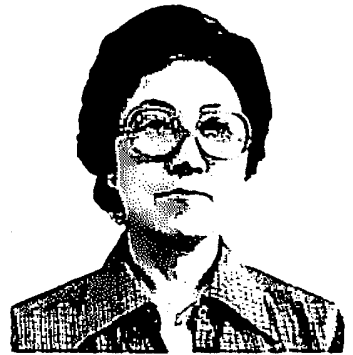

40 Izumi, Masuko

3, 7.1, 7.2, 7.3

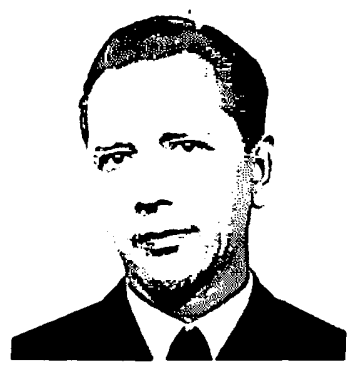

43 Jung, Udo 1, 20.3, 39

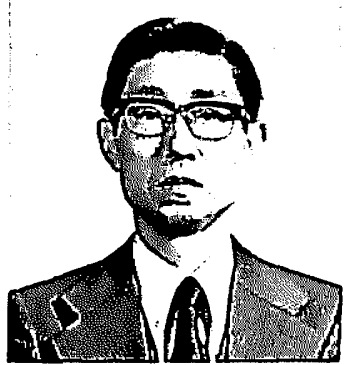

53 Kita, Hiroshi 28

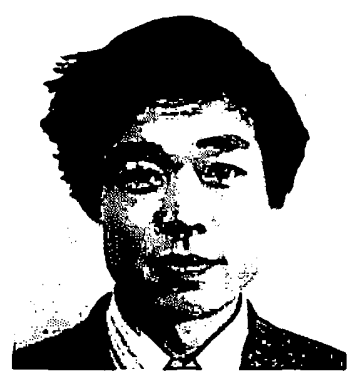

56 Kiyokawa, Hideo 20.1 


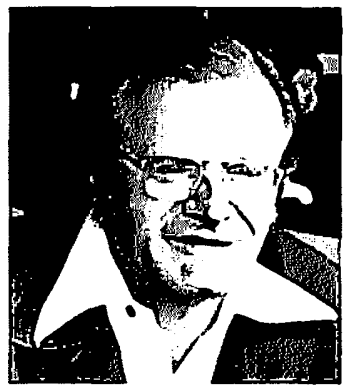

57 Klopf, Donald W. 27.3

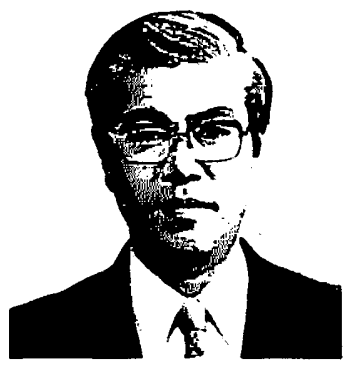

60 Koike, Ikuo 29

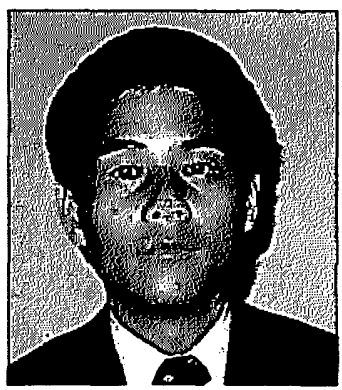

63 Koyama, Shuichi 19.2

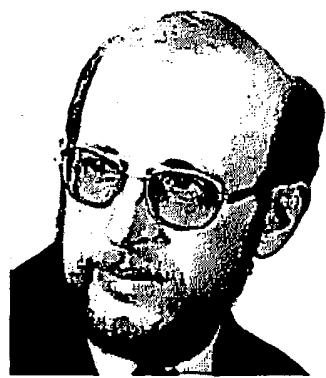

67 Lally, Dale 2, 10, 21, 26, 39

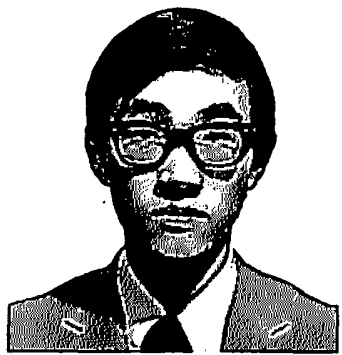

58 Koganei, Takeo

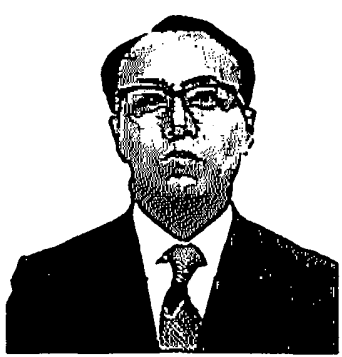

61 Komura, Mikio 20

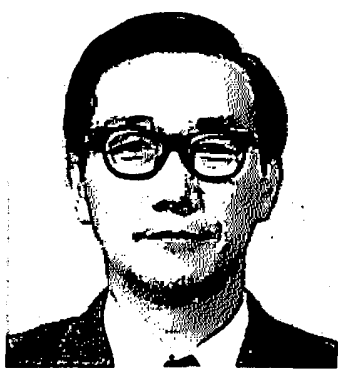

65 Kuriyama, Shoichi

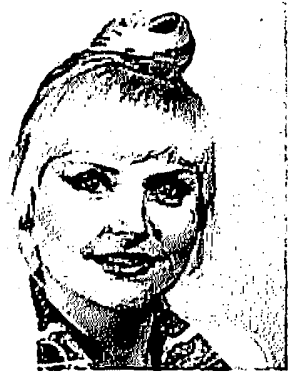

68 Lally, Doris

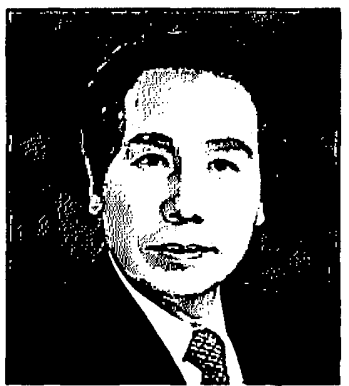

59 Kohamoto, Sutesaburo 1, 38, 39

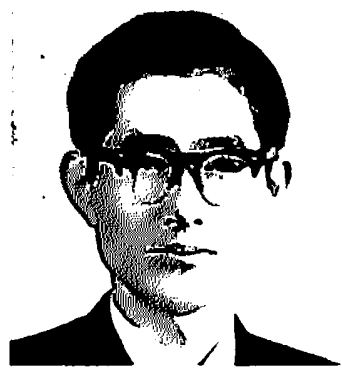

62 Kono, Morio 36

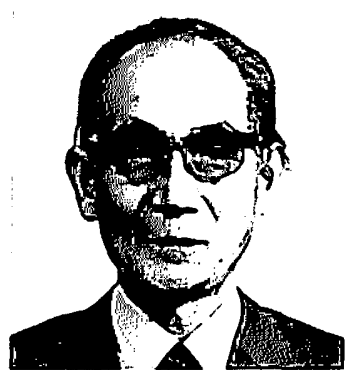

66 Kuroda, Takashi

$$
\text { 1, 6, 7.1, } 39
$$

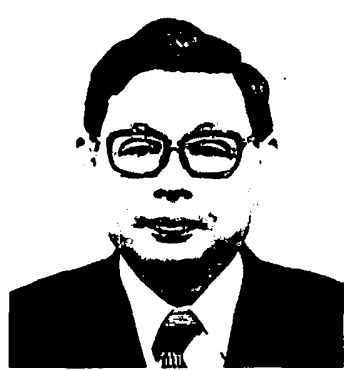

69 Machida, Takaya 23 


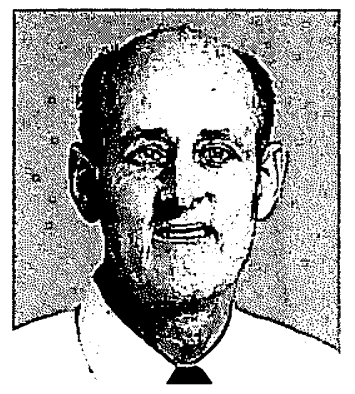

76 McAndrew, Alex 26.4

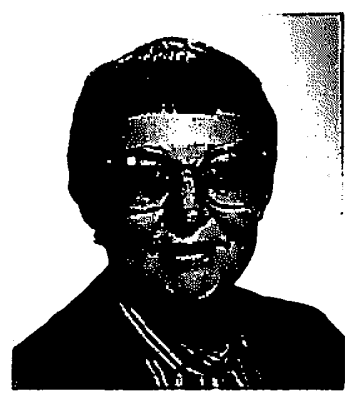

72 Mandelson, Leonore 13.2

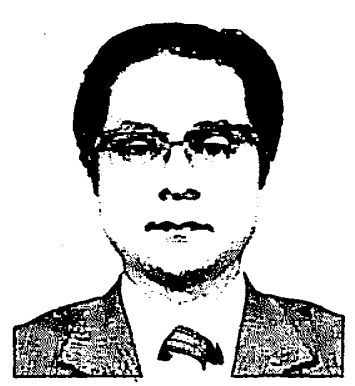

78 Miki, Eichi 26

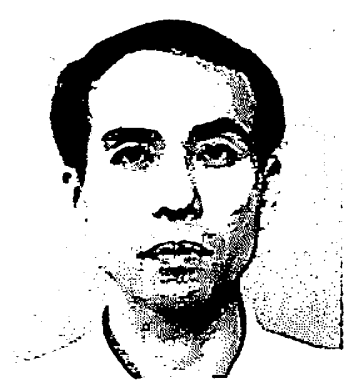

81 Mizumachi, Isao $\mathbf{3 0 . 3}$

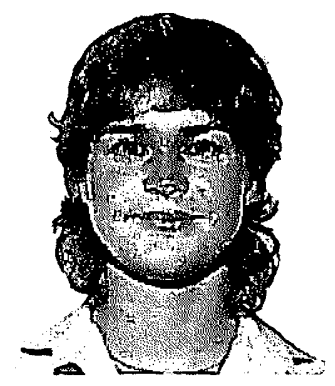

77 McGregor, Karen

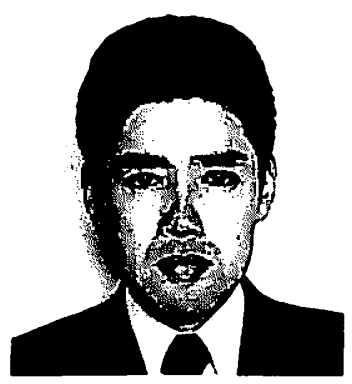

73 Matsuncto, Seiya

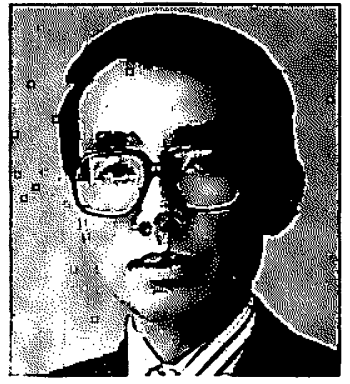

79 Misono, Kazuo

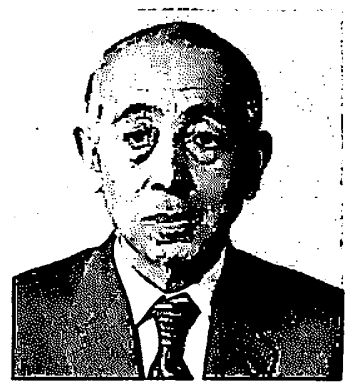

83 Nakajima, Fumio

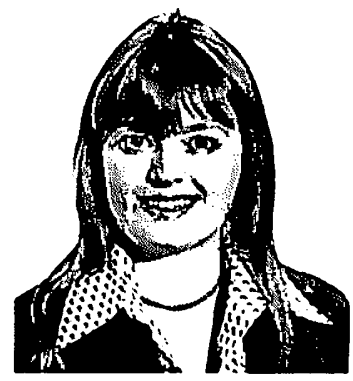

71 Majhanovich, Suzanne 12.1

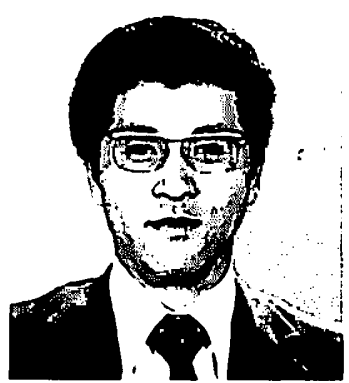

75 Matsuya, Hideaki 23.3

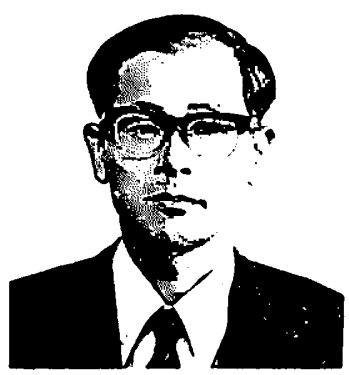

80 Miyahara, Fumio 19

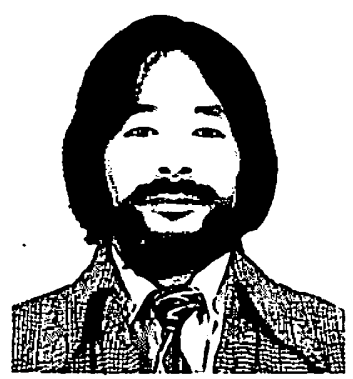

86 Nakayama, Yukihiro $\mathbf{2 2 . 2}$

NALLD Journal 


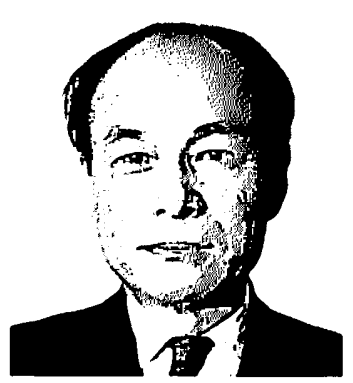

87 Nishimoto, Mitoji

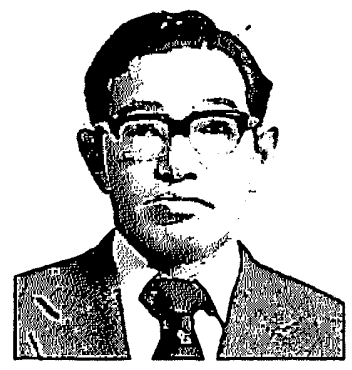

92 Ochiai, Jiro 1, 39

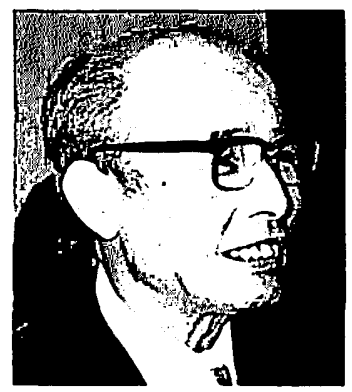

95 Ogawa, Yoshio

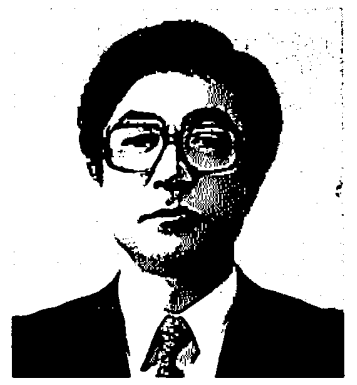

98 Oyagi, Hiroto

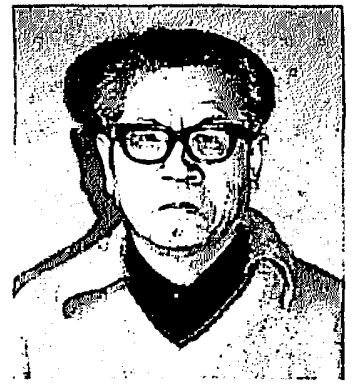

88 Niwa, Yoshinobu 1, 22, 39

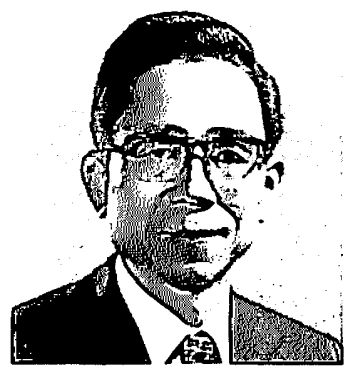

93. Oda, Yukinobu 35

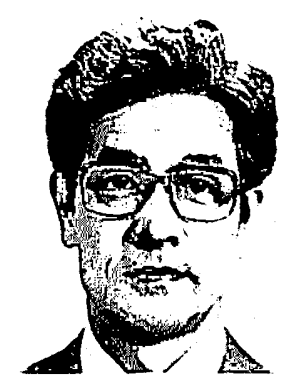

96. Oinoue, Shugeri

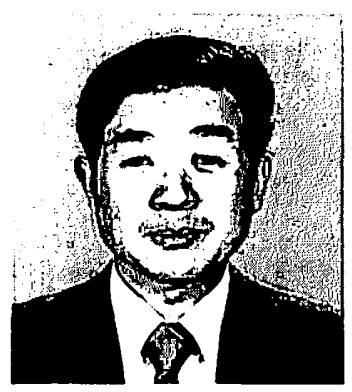

99 Ozawa, Nobuharu 23.3

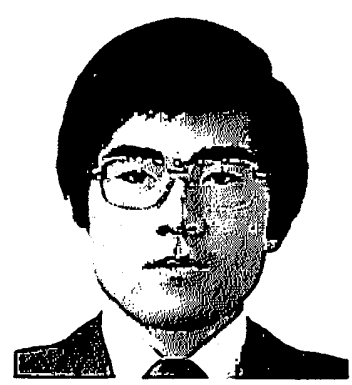

89 Nomura, Kazuhiro 22.3

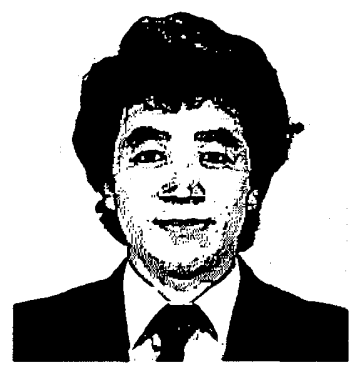

94 Ogawa, Tadao 23.3

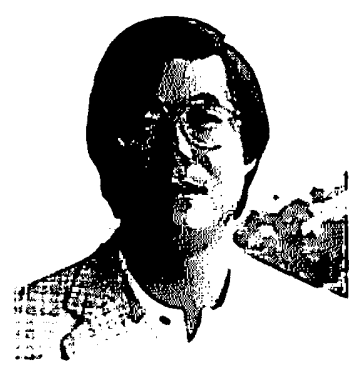

97 Osuģi, Masaaki

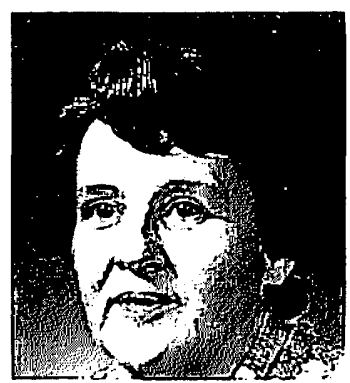

100 Pallister, Janis L. 13.3 


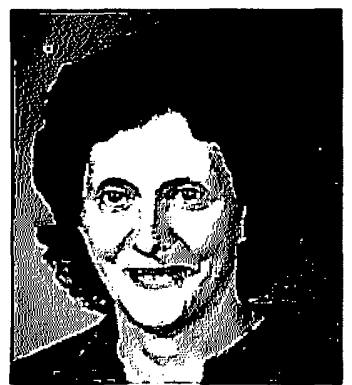

101 Prawer, Florence H. 13.1

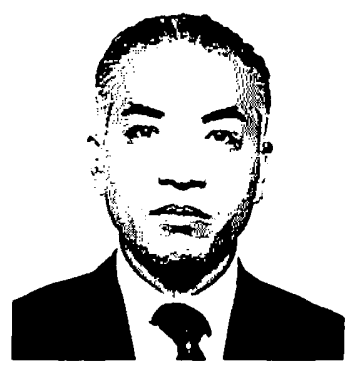

105 Saito, Hiroshi 21.2

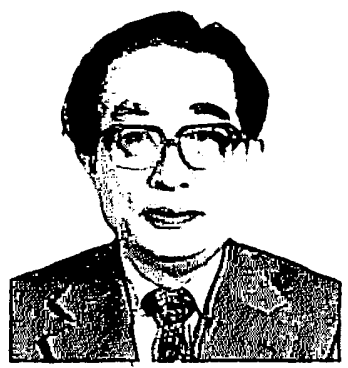

108 Sato, Kazuo 26.1, 31

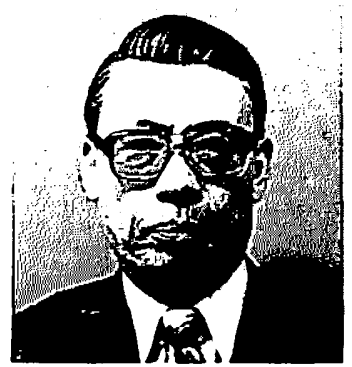

111 Sawamura, Fumio 29

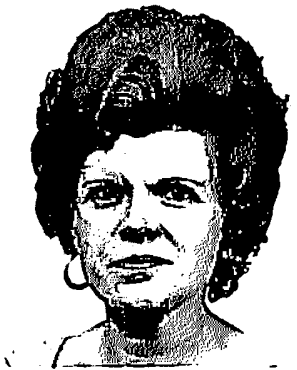

102 Reimers, Theresia 10.3, 22

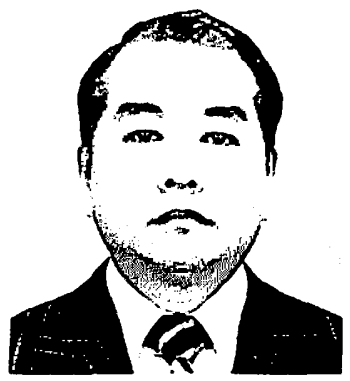

106 Saito, Yasuhiro

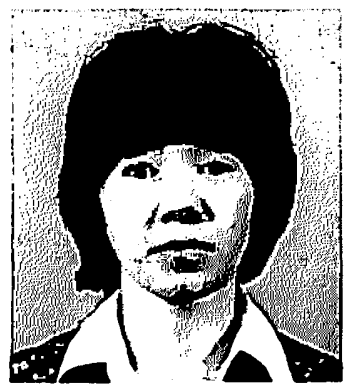

109 Sato, Toyoko

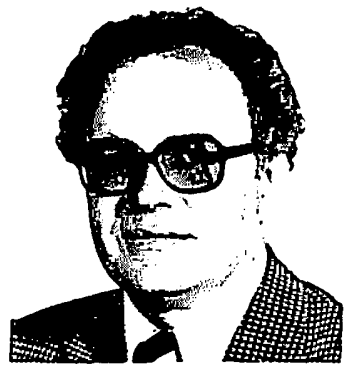

113 Sheehan, Joseph 1, 6, 39

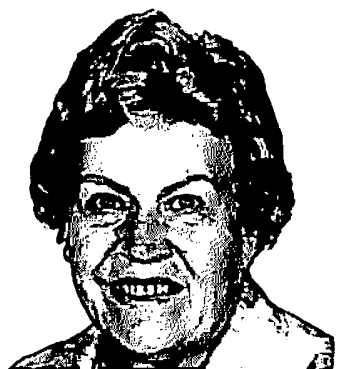

104 Rivers, Wilga 1, 12, 25, 39

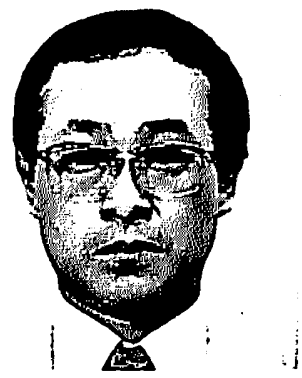

107 Sato, Hajime

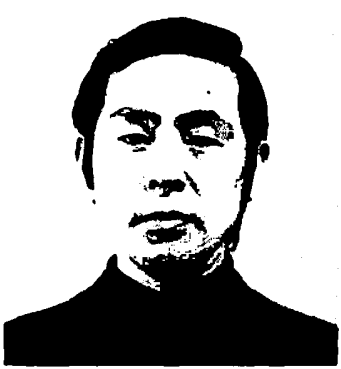

110 Sato, Yasushi 31

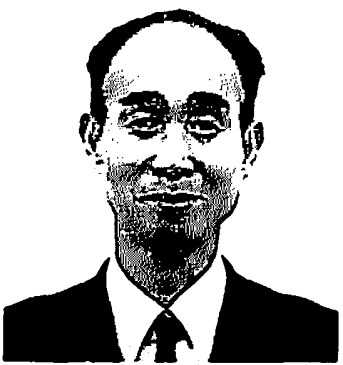

114 Shiigi, Haruo 


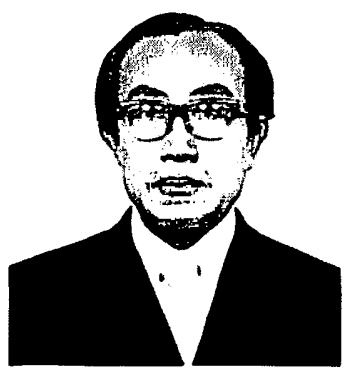

116 Shimada, Masayuki 30.2

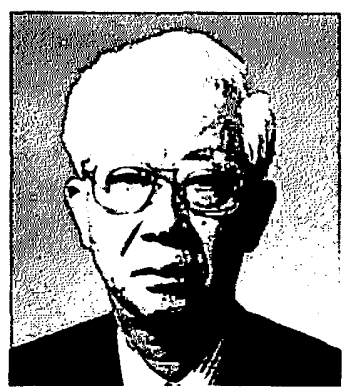

121 Tajima, Hiroshi 1, 39

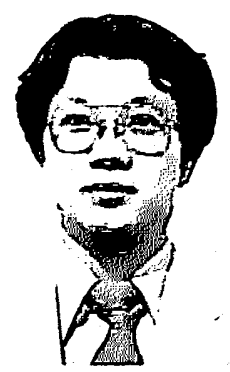

126 Takimoto, Haruo

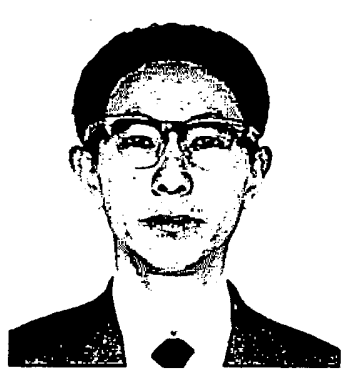

132 Tsukiyama, Hideo 14

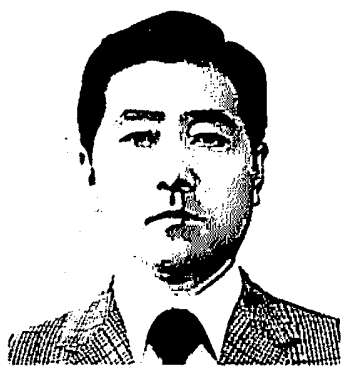

119 Suzuki, Hiroshi 2, 30

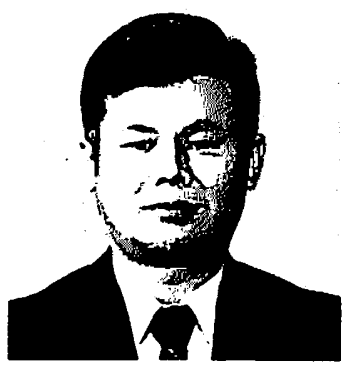

123 Takahashi, Tadashi 23.1

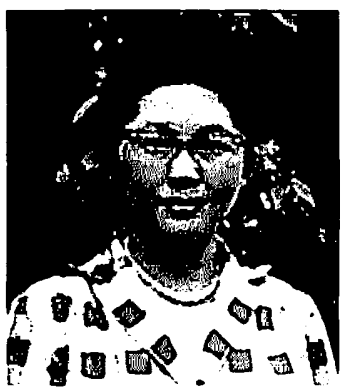

129 Tenma, Michiko 25

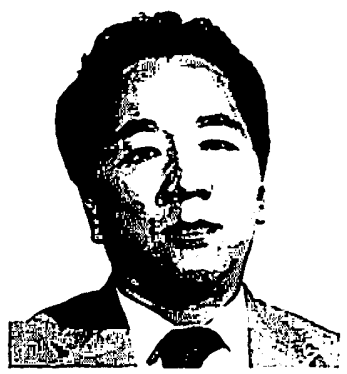

133 Tsuneki, Kiyoshi 27

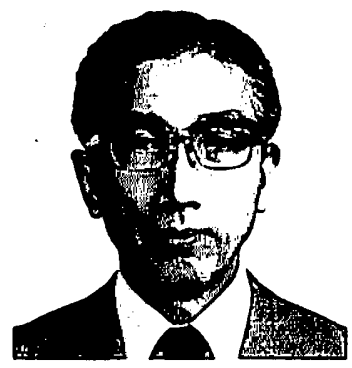

120 Tadokoro, Nobushige 7.2, 7.3, 38

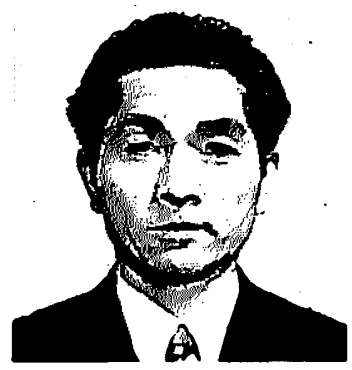

125 Takefuta, Yukio

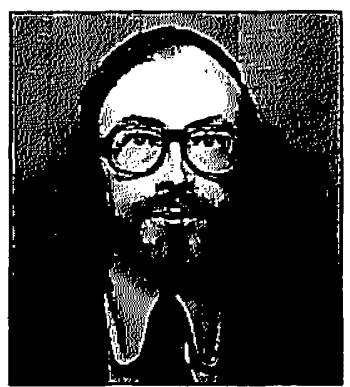

131 Till, Graham

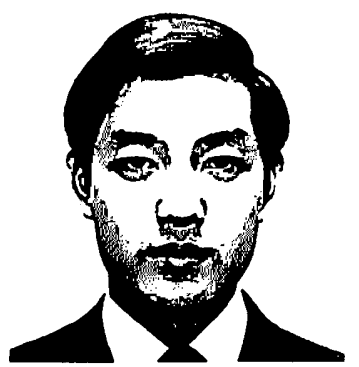

134 Tsuzuki, Masaki 6, 19.4 


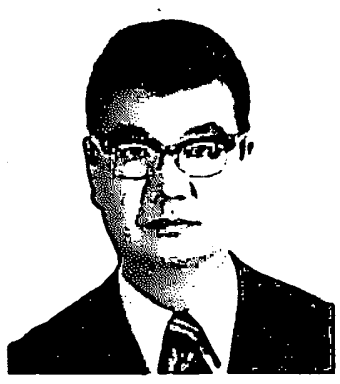

136 Usami, Shozo 9, 34

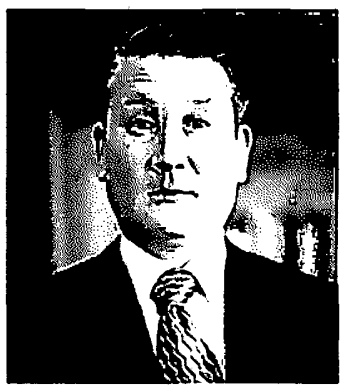

139 Watanabe, Masayoshi

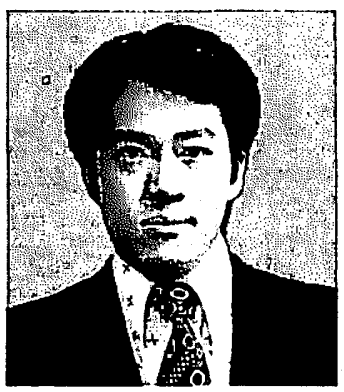

145 Yamane, Shigeru 22.3

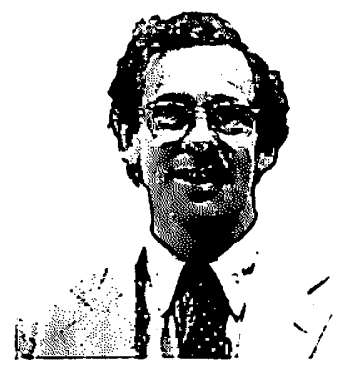

137 Walsh, Terrance $M$.

1, 20, 28.2, 39

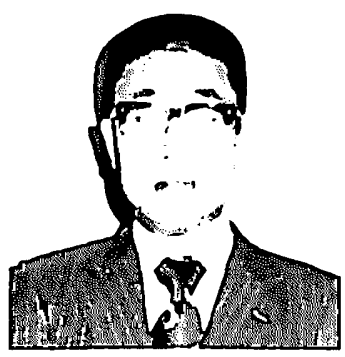

140 Watanabe, Osamu 17

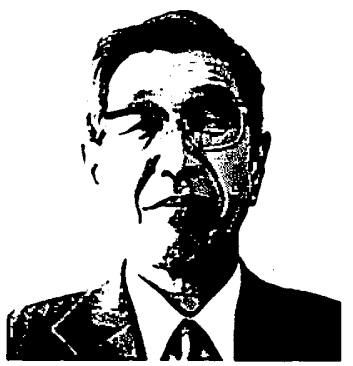

138 Watanabe, Kenkichi 1, 39

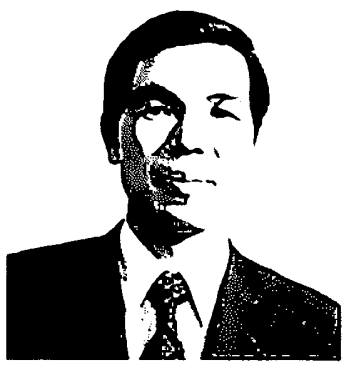

144 Yamada, Noboru 21.1 